Elsevier Editorial System(tm) for The Journal of Chemical Thermodynamics Manuscript Draft

Manuscript Number:

Title: Knudsen thermogravimetry approach to the thermodynamics of aqueous solutions

Article Type: Full Length Article

Keywords: water activity; aqueous solutions; thermo-gravimetry

Corresponding Author: Prof. Alberto Schiraldi, PhD

Corresponding Author's Institution: University of Milan

First Author: Alberto Schiraldi, PhD

Order of Authors: Alberto Schiraldi, PhD

Abstract: The use of isothermal TGA with Knudsen-like cells allows determination of the thermodynamic activity of water, aW. The typical experiment implies a slow dehydration of the aqueous solution at constant temperature in dynamic vacuum conditions. The method is alternative to the classical isopiestic approach and offers the advantage of a continuous record on increasing the solute concentration. These data can be directly treated according to the classical thermodynamic relationships drawn from the Gibbs-Duhem expression to evaluate the activity and osmotic coefficient of the aqueous solutions of electrolytes and non-electrolytes, and, in the case of electrolytes, allow determination of solubility of the solute. Discrepancies with respect to the literature data are observed when the viscosity of the systems becomes too high, as in the case of sugars with a very large solubility. Such a mismatch may however be accounted for either slowing the dehydration rate with use of a narrower Knudsen orifice, or correcting the experimental aW with a calibration curve. The same approach can be applied to non-aqueous solutions. 


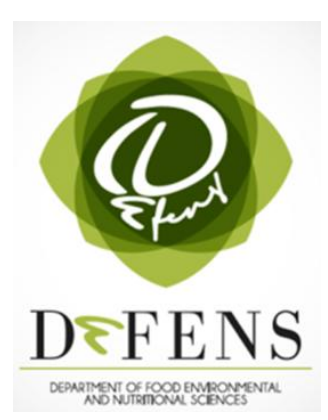

\section{Drof. Alberto Qschiraldi}

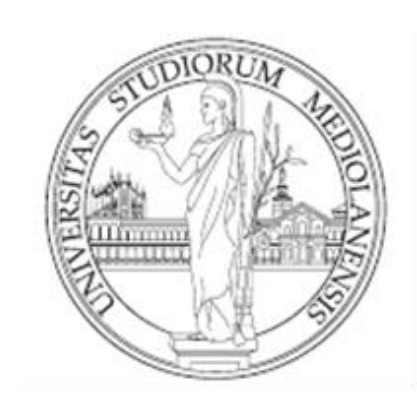

To the Editor of

The Journal of Chemical Thermodynamics

Cover Letter for the paper "Knudsen thermogravimetry approach to the thermodynamics of aqueous solutions" by Alberto Schiraldi, Marco Signorelli and Dimitrios Fessas.

\section{Dear Editor,}

Here attached please find the manuscript we submit for publication in JCT. The paper proposes a new approach for the experimental determination of the thermodynamic activity of water, which is so important in the characterization of life-related systems, that have been a major research subject of our laboratory of calorimetry and thermal analysis at the DeFENS of the University of Milan..

In a first moment we had the intention to patent the method, but, being strongly solicited by colleagues of ICTAC and our national association of Calorimetry and Thermal Analysis (AICAT), we eventually decided to freely spread the information about the details of the equipment, namely the Knudsen-like cell, providing also a dedicated discussion about the weakness points, just to suggest possible improvements that may be required to enhance accuracy and sensitivity of the method.

The application to simple aqueous solutions of 1:1 strong electrolyte and sugars has been reported to make the message of the paper closer to traditional subjects of Chemical Thermodynamics that are certainly familiar to most of JCT readers.

Looking forward receiving your acknowledgement, sincerely yours

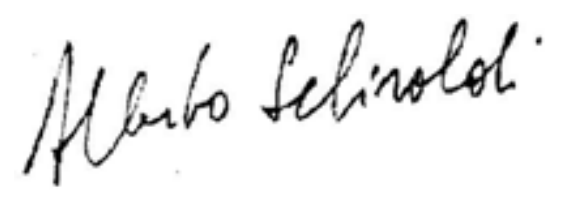

Alberto Schiraldi 


\section{Highlights}

- Knudsen effusion is directly related to the vapor pressure within a Knudsen Cell;

- Water Activity, a(W), may be approximated by the $\mathrm{p}(\mathrm{W}) / \mathrm{p}(\mathrm{W})$ * ratio;

- An isothermal desorption TG run performed with Knudsen cell allows determination of a(W) changes on increasing the concentration of solutes;

- A Knudsen-like cell is here proposed to replace the standard TG pans and perform the above determination;

- The method is alternative to the traditional isopiestic approach;

- Examples are given on concentrated aqueous solutions of electrolytes and sugars; 


\title{
Knudsen thermogravimetry approach to the thermodynamics of aqueous solutions.
}

\author{
Alberto Schiraldi, Marco Signorelli and Dimitrios Fessas \\ Department of Food, Environmental and Nutritional Sciences \\ University of Mila (Italy), via Celoria 2, 20133 Milano (Italy)
}

\begin{abstract}
The use of isothermal TGA with Knudsen-like cells allows determination of the thermodynamic activity of water, $a_{\mathrm{W}}$. The typical experiment implies a slow dehydration of the aqueous solution at constant temperature in dynamic vacuum conditions. The method is alternative to the classical isopiestic approach and offers the advantage of a continuous record on increasing the solute concentration. These data can be directly treated according to the classical thermodynamic relationships drawn from the Gibbs-Duhem expression to evaluate the activity and osmotic coefficient of the aqueous solutions of electrolytes and non-electrolytes, and, in the case of electrolytes, allow determination of solubility of the solute. Discrepancies with respect to the literature data are observed when the viscosity of the systems becomes too high, as in the case of sugars with a very large solubility. Such a mismatch may however be accounted for either slowing the dehydration rate with use of a narrower Knudsen orifice, or correcting the experimental $a_{\mathrm{W}}$ with a calibration curve. The same approach can be applied to non-aqueous solutions.
\end{abstract}

\section{INTRODUCTION}

Aqueous solutions of simple electrolytes and non-electrolytes are still a largely investigated subject, since a better understanding of these systems is of great help in many fields of science and technology. The reported investigations mostly deal with diluted aqueous solutions, where the socalled strong electrolytes are supposed to be totally dissociated and the dissociation of weak electrolytes and the solvation of non-electrolytes are mainly governed by the interactions with water. Nature and strength of the interactions between these solutes and water, as well as the dissociation degree of salts, have been so far referred to as major issues of the theoretical approaches and experimental investigations [1-11], a summary of which can be found in recent review papers $[12,13]$. Computational models [14-21] were also developed to predict the value of the activity or osmotic coefficient of the solute and compare the results with literature data which mainly come from isopiestic or electrochemical investigations. Theoretical models and experimental approaches so far exploited seem rather adequate to describe the solute-water interactions, which prevail at low and very low concentration, but become much less reliable for larger solute concentration $[22,23]$, which imply stronger solute-solute interactions and produce important changes of other physical properties of the solution, like medium viscosity and molecular mobility, that can directly affect the results obtained with some experimental technique, including 
the classical electrochemical methods. Further difficulties are met when non-aqueous solutions are considered $[11,14]$.

Concentrated aqueous phases are indeed of outmost importance in life-sciences, since water availability and water displacements and water partition govern many biological and physiological functions in living organisms, and technological processes in food, cosmetic and pharmaceutical applications.

As an example, a basic requirement for the preservation of food is the control of water activity, $a_{\mathrm{W}}$, which has been empirically correlated [24] with a number of deteriorating effects that severely reduce the shelf-life of the products and their safety. For this reason a number [25] of experimental techniques have been exploited to reproduce the results of the isopiestic procedure which is the reference for all of them. In a typical isopiestic investigation the system of interest is "equilibrated" with a saturated salt solution of known water activity, $a_{\mathrm{W}}$, and the relevant mass change is determined. This procedure is repeated with a series of different saturated salt solutions so as to empirically assess the adsoption/desorption isotherm relevant to the system considered. Were the actual stability of food products compatible with the duration of the "equilibration" process, such an approach would be fully reliable. Unfortunately, the wide adsorption/desorption hysteresys found for many products $[25,26]$ and the long equilibration time required especially for "dry products" can actually affect the reliability of the evaluations. What is more, when the temperature of the sample is below the relevant glass transition threshold, $\mathrm{Tg}$, a real equilibrium is never reached (since below such a threshold the molecular mobility decreases by several orders of magnitude) and no reliable detection of $a_{\mathrm{W}}$ is possible. For this reason the concept of "critical $a_{\mathrm{W}}$ " [26], that accounts for the reduced mobility of water molecules in the vicinity of the glass transition, has to be considered. A simplistic way to account for the effects of a large medium viscosity on the experimental $a_{\mathrm{W}}$ data is to referred the latter to as apparent $a_{\mathrm{W}}$, that can be related to the "true" $a_{\mathrm{W}}$ by a correction factor $\left(\eta / \eta^{*}\right)$, namely the ratio between the viscosity of the aqueous solution considered and that of pure water at the same temperature (see appendix of [27]). The multi-phase character of many biological systems is another issue of interest related to the reliability of the experimental approaches to $a_{\mathrm{W}}$ [27].

To overcome the problem of the duration of the experiment, our group developed [28] an approach based on the use of isothermal thermogravimetry in Knudsen-like conditions (Knudsen TG, see below). This methods allows the whole desorption isotherm of a given moist product to be drawn from a single 2-3 hour experiment with an overall reproducibility of about $1 \%$ for $a_{\mathrm{W}} \geq 0.8$ and $2 \%$ for $a_{\mathrm{W}}<0.8$. A reference run (at the same temperature and with the same Knudsen cell) with a pure water sample is required for the evaluation of $a_{\mathrm{W}}$. A peculiarity of the equipment used is 
the simultaneous detection of mass loss (dehydration) and relevant thermal effect, as the pans of the thermo-balance are suspended within the cylindrical cavities of a twin Calvet calorimeter. The method was validated by comparing measured and expected $a_{\mathrm{W}}$ values of saturated salt solutions [28].

The reliability of the results so far obtained for food systems $[29,30]$ suggested the use of the Knudsen-TG to investigate aqueous electolytes and non-electrolytes in a wide concentration range, up to the respective saturation level, as an alternative to the classical isopiestic approach to evaluate $a_{\mathrm{W}}$ and, via the Gibbs-Duhem relationship, the thermodynamic activity of the solute and the respective osmotic and activity coefficients.

The present work reports the results obtained for aqueous solutions of some simple strong electrolytes, like $\mathrm{NaCl}, \mathrm{KCl}, \mathrm{KNO}_{3}$, and some non-electolytes, like glucose, fructose, maltose and sucrose, in isothermal conditions at $25^{\circ} \mathrm{C}$.

\section{MATERIALS and METHODS}

The instrument used (Tg-DSC 111, SETARAM, France) provides the simultaneous record of: mass loss, $\Delta m$, mass loss rate, $\mathrm{d} m / \mathrm{d} t$, and heat flux, $H F=\mathrm{d} Q / \mathrm{d} t$. In a Knudsen $\mathrm{TG}$ experiment the temperature is kept constant with an ad hoc thermal programme of the instrument. The effusion through the cell orifice (see below) is driven by the dynamic vacuum ( $p<10^{-4} \mathrm{~mm} \mathrm{Hg}$ ) produced with a turbo-molecular pump. If pure water (or any other pure compound) is examined, the ratio between heat flux and mass loss rate corresponds the vaporization enthalpy at the temperature considered:

$$
\frac{\mathrm{d} Q / \mathrm{d} t}{\mathrm{~d} m / \mathrm{d} t}=\frac{\mathrm{d} Q}{\mathrm{~d} m}=\Delta_{\mathrm{vap}} H
$$

This is also the case of water evaporation from a sub-saturated salt solution. As the only process that is taking place during the TG run is just the dehydration of the sample, the comparison with the standard $\Delta_{\text {vap }} H\left(\mathrm{H}_{2} \mathrm{O}\right)$ value allows a direct calibration of the heat flux.

\section{Knudsen regime}

The Knudsen effusion is the flow of gas through an orifice pierced in an infinitely thin frame which has no walls [31]. The orifice has a diameter comparable to the mean free path of a gas molecule $(1-10 \mu \mathrm{m}$, according to the pressure and temperature). All the gas molecules with a displacement component perpendicular to the orifice plane and trajectories that cross the orifice area can trespass the frame without changing their own speed. In these conditions, an isothermal 
Knudsen effusion implies a linear correlation between the mass flux and the pressure drop across the orifice,

$$
F \propto\left(p_{\text {in }}-p_{\text {out }}\right)
$$

Were such a frame the cover of a cell containing a pure volatile compound, $p_{\text {in }}$ would be equal to the relevant equilibrium vapour pressure, $p^{*}$, at the temperature considered, and the effusion flow would correspond to the mass loss rate, $\mathrm{d} m / \mathrm{d} t$. When $p_{\text {out }}$ " $p_{\text {in }}$, the mass loss rate would depend only on $p^{*}$, namely,

$$
\mathrm{d} m / \mathrm{d} t \propto p^{*}
$$

and, at constant temperature, it would be constant. This is also the case of a saturated salt solution, the water activity of which may be related to the water vapour pressure ratio, $a_{\mathrm{w}} \approx p_{\text {sat }} / p^{*}$ (where "*" stands for pure water), and can therefore be determined as the ratio between the mass loss rates determined in two separate experimental runs (with the same cell, at the same temperature and vacuum conditions), for the salt solution and pure water, respectively:

$$
a_{w} \approx \frac{p_{s a t}}{p^{*}}=\frac{(d m / d t)_{s a t}}{(d m / d t)^{*}}
$$

With this in mind, the detection of the mass loss rate of an ideal Knudsen cell could be referred to as a reliable method to evaluate the vapour pressure of any compound at any temperature.

To put in practice this idea, a commercial thermobalance can be used once its standard pan(s) are replaced with a Knudsen-like cell (see below). All the above expectations can however be met only when the effusion through the cell orifice actually mimics that of an ideal Knudsen cell, which should have an infinitely thin cover. For the practical construction of the device, it is instead necessary to design a cell cover thick enough to allow a tight screwing. Unfortunately, the effusion rate through any hole across a finite thickness cover cannot be related to the first power of the pressure drop (see equation 1), but follows a higher order law, like that for a turbulent flow along a pipe. For this reason a peculiar Knudsen-like cell has to be designed.

\section{A Knudsen-like cell}

To overcome this difficulty, the standard pan of the thermo-balance was replaced with a small cylinder with a vacumm proof screwed cover. This was pierced with a laser beam that produced a hole with conical walls narrowing towards the exterior of the cell (Figure 1). 


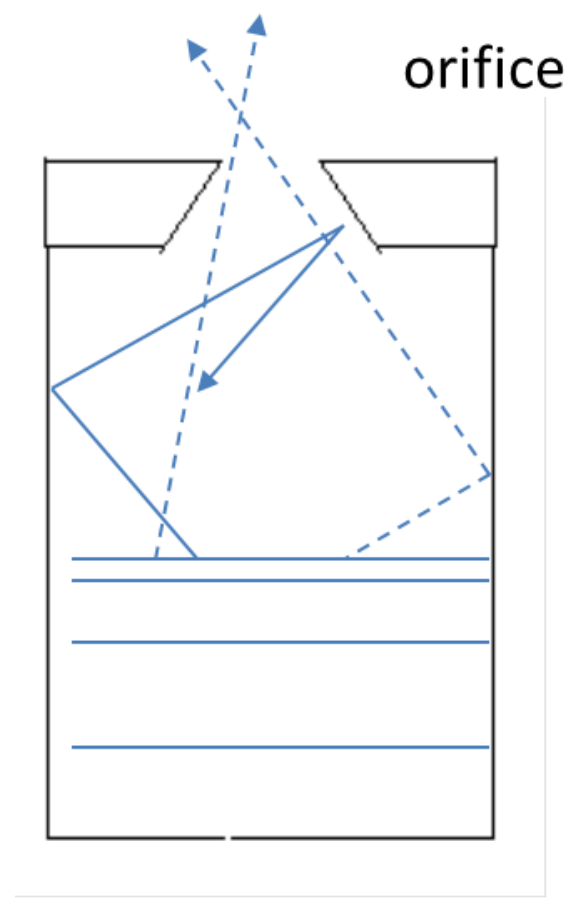

\title{
Cell cover
}

\author{
Head space
}

\section{Liquid phase}

Figure 1. Knudsen-like cell hosting a liquid phase. The orifice pierced through the cover actually has an outer diameter of 20 micrometers and a conical shape (see text). Dotted lines mimic the trajectories of molecules able to freely effuse through the orifice.

The rationale beneath this choice is that most of the outbound vapour molecules would collide onto the hole walls and bounce back to the interior of the cell (cosine low [32]). Only the molecules with trajectories within the solid angle of the conical opening would trespass the outer orifice without experiencing collisions and turbulences, just as the molecules in a true Knudsen effusion process.

To achieve this goal, the focus of the laser beam used to pierce the cell covers was adjusted to obtain outer orifices of various size $(20,30,50 \mu \mathrm{m})$, each matched with solid angles of the conical hole of various width. These Knudsen-like cells were preliminary tested to verify whether the mass loss rates observed for pure water and saturated salt solutions were actually constant throughout the effusion process in isothermal conditions (Figure. 2). 


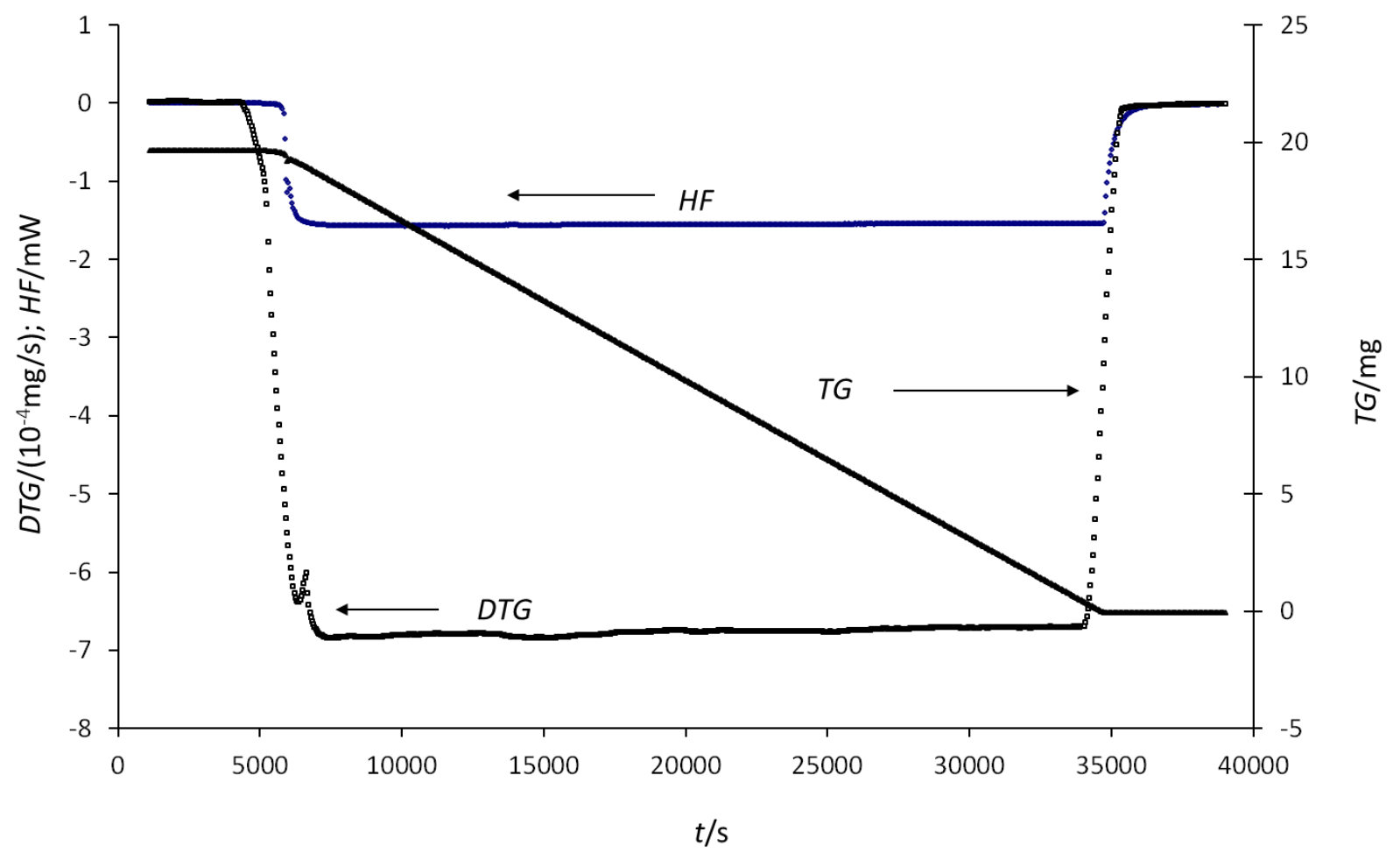

Figure 2. Records of the TG, $H F$ and DTG traces of a sample of pure water at $25^{\circ} \mathrm{C}$.

A constant mass loss rate however reflects a balance between the outbound flow of molecules through the cell orifice and the evaporation rate within cell. This steady condition does not necessarily mimic the true thermodynamic equilibrium, since it involves the molecular mobility through the liquid phase. Furthermore, if the liquid phase is a saturated salt solution, the simultaneous segregation of the solute may produce concentration gradients across the solution. Finally, if the effusion rate is too high, liquid micro-drops can be stripped away and clog the cell orifice, an accident that may also occur because of the formation of vapour micro-bubbles. To find conditions consistent with equation 2 , comparison with reference data is mandatory.

Since flat $D T G$ (time derivative of the mass loss) traces were always found for pure water samples and a number of saturated salt solutions, no matter the size of the cell orifice, the relevant ratios (obtained with data from the same cell, see equation 3) could be reliably evaluated and compared with the $a_{\mathrm{W}}$ values expected for various saturated salt solutions (Figure 3). 


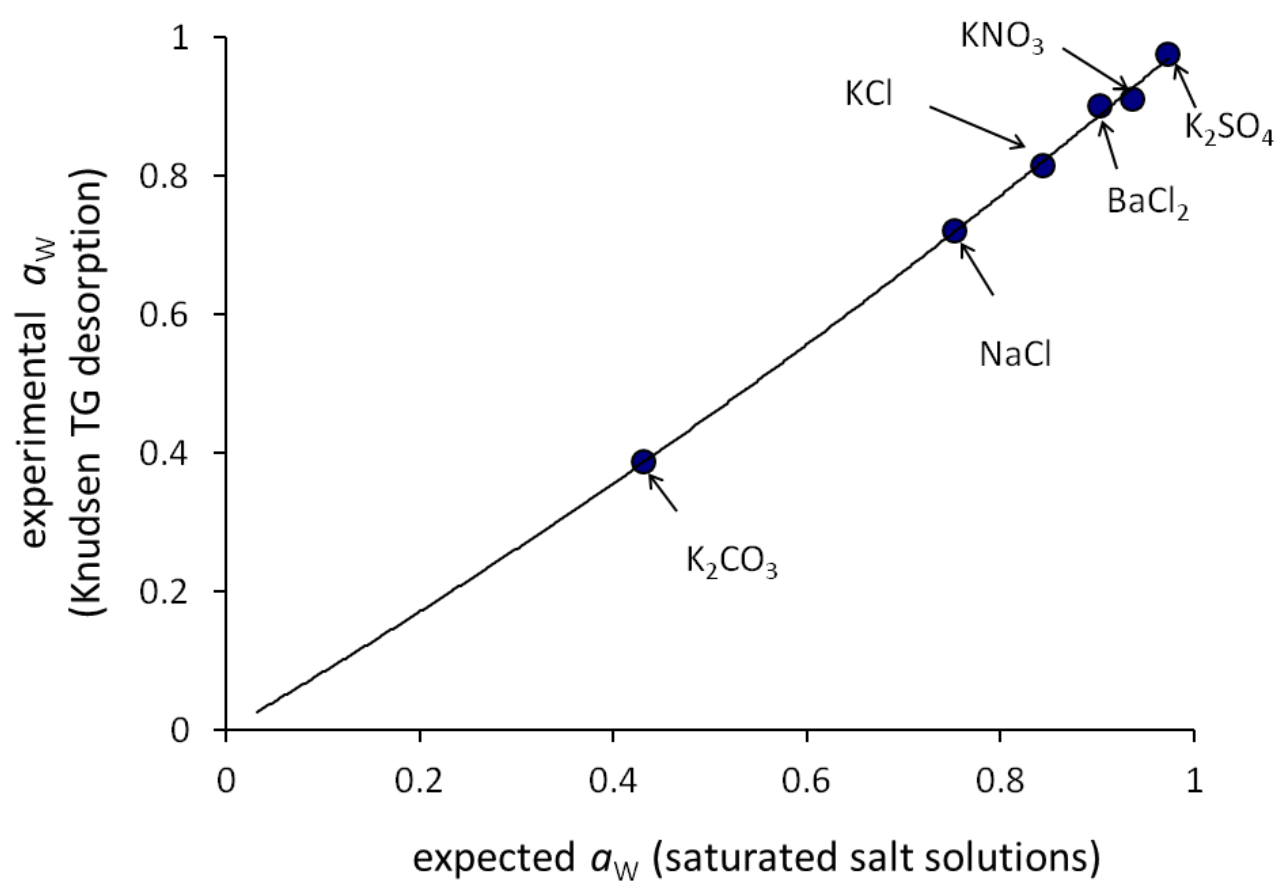

Figure 3. Matching between expected (literature) and Knudsen Thermogravimetry $a_{W}$ data from saturated aqueous salts. The heavy correlation straight line (see text) was determined for a 20 micrometer cell orifice. Literature data from [33].

The agreement was rather satisfactory for $a_{\mathrm{W}} \geq 0.8$, for any considered size of the cell orifice, while deviations were observed for lower $a_{\mathrm{W}}$ values. Such deviations however showed a well-defined trend for each given Knudsen-like cell, being smaller for cells with wider orifices. This finding indicated that the effects of such deviations could be eliminated by selecting the most appropriate Knudsen-like cell for a given solution, or reliably accounted for with a calibration curve. For a 20 micrometer orifice, the calibration implied a parabolic correction trend, namely

$$
a_{\mathrm{W}}=a_{\mathrm{W} \exp }\left(1.1871-0.1919 a_{\mathrm{W} \exp }\right)
$$

In the present work a cell with a 20 micron orifice was used for all the aqueous solutions considered. The above calibration curve was used to adjust the experimental $a_{\mathrm{W}}$ trend of a Knudsen dehydration as $a_{\mathrm{W}}$ decreases during the run. This empirical adjustment therefore accounts for the increase of medium viscosity on the $a_{\mathrm{W}}$ value (see appendix of [27]).

\section{Materials}

Twice distilled water was used to prepare all the aqueous solutions considered. The salts, i.e., $\mathrm{NaCl}, \mathrm{KCl}, \mathrm{KNO}_{3}$, and the sugars, i.e., glucose, fructose, sucrose and maltose, were reagent grade commercial products (Sigma Aldrich). The typical sample mass was about $30 \mathrm{mg}$. The starting concentration was around $2 \mathrm{~mol} / \mathrm{kg}$ of water, as the main scope of the work was to investigate concentrated solutions. 
Just after or before a Knudsen TG run with the solution of interest, the same cell was used to perform a run with a pure water sample at the same vacuum and temperature conditions. The latter gave a flat horizontal DTG trace that allowed a very reliable determination of the mean constant value to be used for the evaluation of $a_{\mathrm{W}}$ (see above).

The aqueous solutions were prepared with known solute/solvent mass ratio, $m_{\mathrm{S}} / m_{\mathrm{W}}(0)$. Since the mass loss during the Knudsen TG run concerns only the solvent (while the solute mass remains constant), the residual solvent mass, $m_{\mathrm{W}}(t)$, can be easily assessed at any time of the experiment (see Figure 2). This means that the desorption isotherm, namely, $\left(m_{\mathrm{W}} / m_{\mathrm{S}}\right)$ versus $a_{\mathrm{W}}$, can be easily drawn from a single Knudsen TG experiment. In the present work this information was given in the

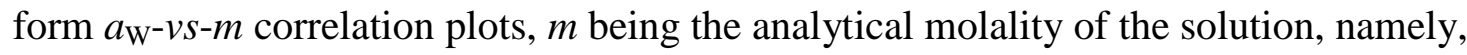
$m(t)=\frac{m_{S}}{m_{W}} \frac{10^{3}}{M_{S}}$,

where $M_{\mathrm{S}}$ is the molecular mass of the solute.

\section{RESULTS AND DISCUSSION}

\section{Solubility of salts}

When water is sucked out from a Knudsen TG cell hosting a salt solution with a starting concentration below the saturation level, the relevant $D T G$ trace shows a bending trend, as $a_{\mathrm{w}}$ decreases, while the solute concentration increases during the run. This trend shows no break when the concentration crosses the saturation threshold, since the solution undergoes super-saturation, possibly because of a small homogeneous nucleation rate. In the case of aqueous electrolytes, this metastable situation lasts until an abrupt change occurs at the onset of the solute precipitation. The $D T G$ trace shows an upward drift and finally attains the horizontal trend expected for a saturated solution (Figure 4). The evidence collected in the present work showed that the delay of equilibrium recovering changed from sample to sample for any given salt solution, thus confirming the metastable character of the super-saturation (Figure 5). 


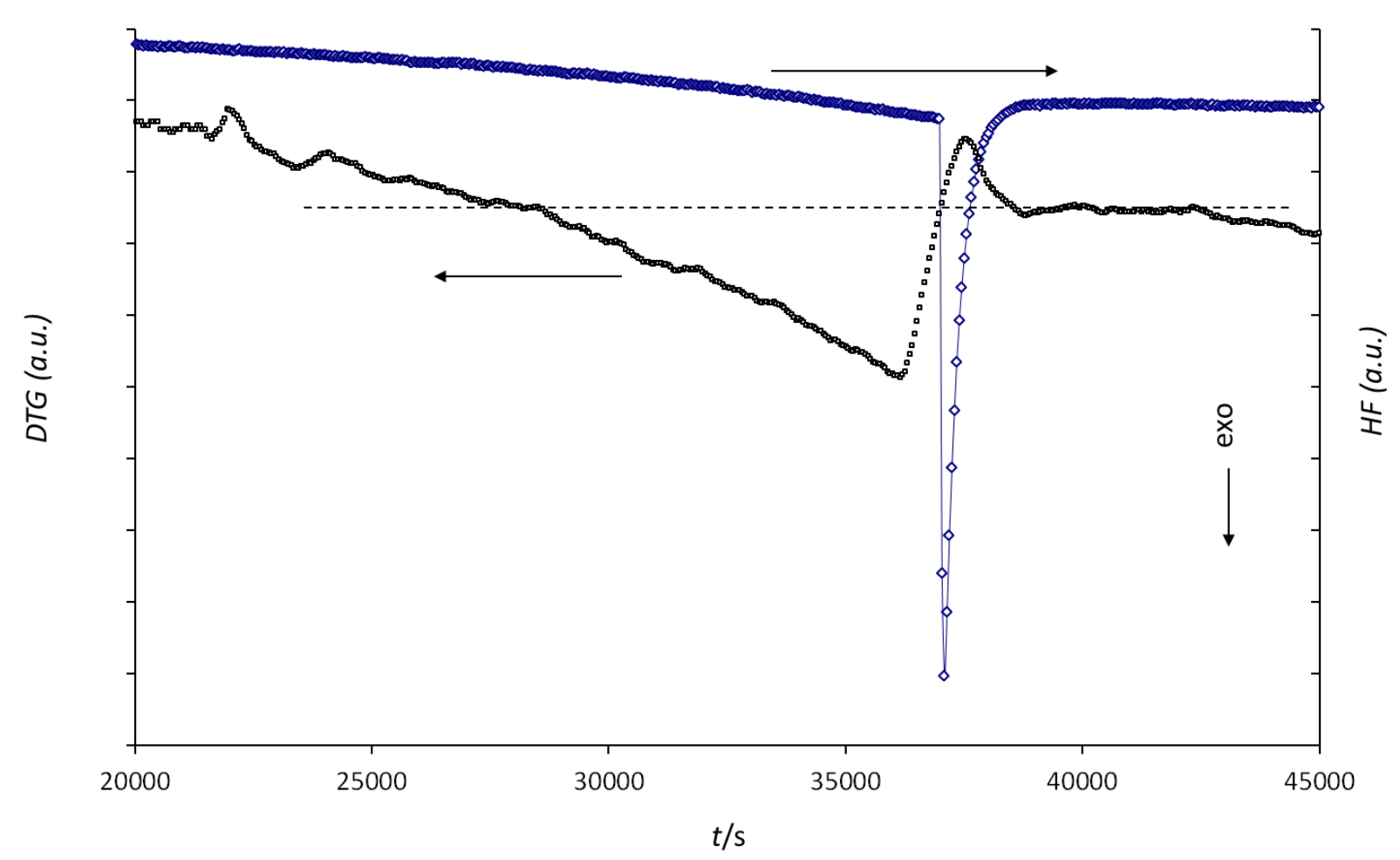

Figure 4. Isothermal $\left(25^{\circ} \mathrm{C}\right) \mathrm{Knudsen}$ DTG trace recorded from a $\mathrm{KNO}_{3}$ aqueous solution. The dashed line corresponds to the flat trend of the saturated solution. In the special case of $\mathrm{KNO}_{3}$, the early phase of the salt precipitation is accompained by a transient subsaturation step that confirms the non-equilibrium condition of this process (see text). The simultaneous heat flux trace $(H F)$ shows an exothermic peak.

The trace of the simultaneous record of the heat flow, $H F$, was parallel to that of the mass loss rate during the slow dehydration of the starting solution, while an exothermic peak appeared just at the DTG upward drift. This finding was in line with the expected start of the salt precipitation. Once the $D T G$ trace attained the flat trend related to the saturation state, the $H F$ trace too became constant ${ }^{\perp}$.

If the horizontal line that fits the flat final part of the such a DTG trace is extrapolated back to cross the previous bending trend, the solubility of the salt can be evaluated as the molality at the cross point (see Figure 4). This result can therefore be achieved with a single Knudsen TG experiment. Replicas allow determination of the relevant confidence limits.

$\perp$ The bending of the first region of the DTG trace reflects the increase of $a_{W}$ during the slow dehydration of the solution. In the case of aqueous salts, this trend trespasses the solubility threshold without any discontinuity (i.e., the solution becomes super-saturated) and goes through a minimum followed by an upward drift (simultaneous to the precipitation of the excess solute) that can exceed the plateau expected for the saturation (see the case of $\mathrm{KNO}_{3}$ in Fig. 4), i.e., the solution experiences sub-saturation before attaining the saturation state. This sub-saturation step was always observed for $\mathrm{KNO}_{3}$, although its extent could vary from sample to sample, while it was only occasionally observed for the other salts. The super-saturation was instead observed for every aqueous salt considered in this work. 

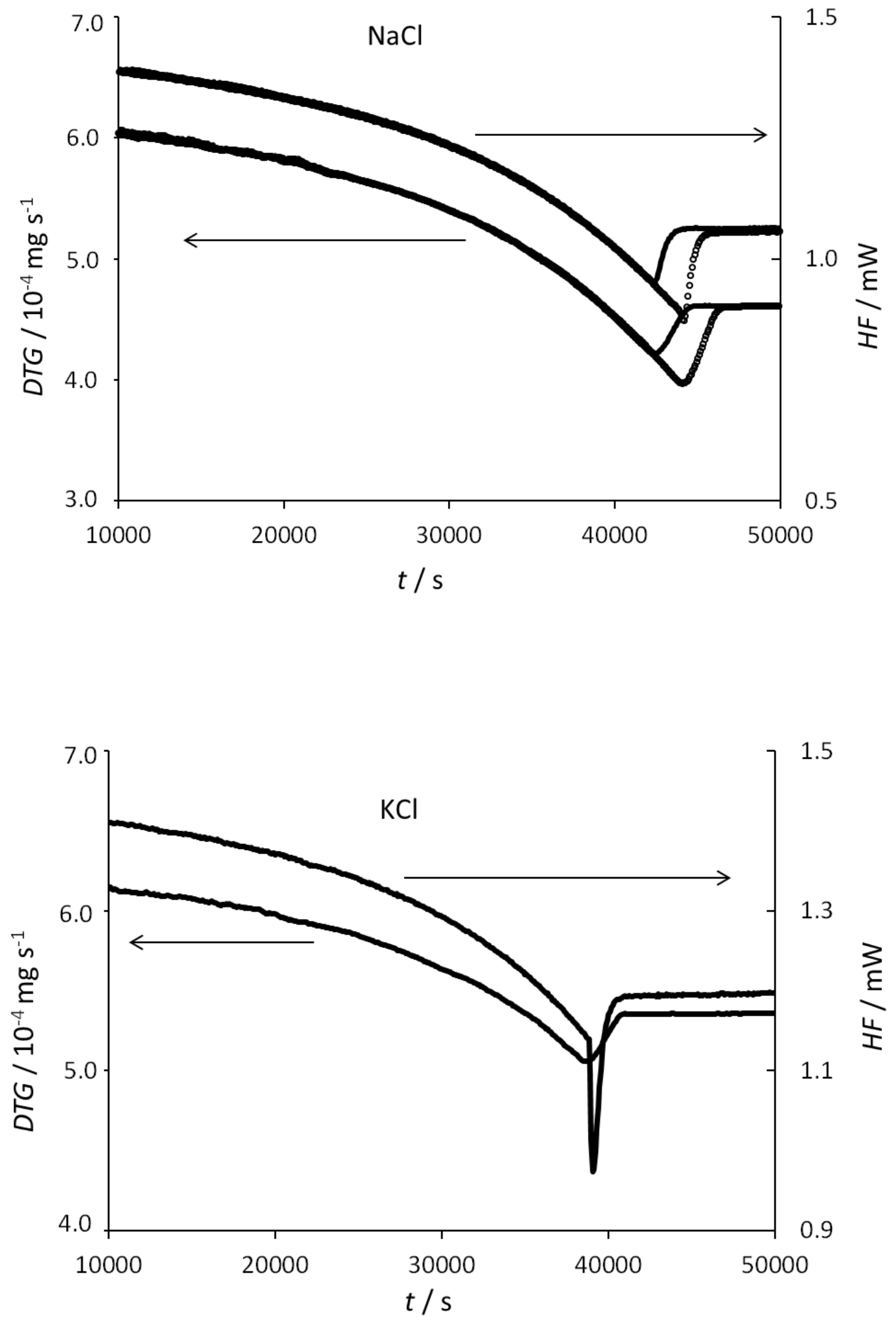

Figure 5. DTG and HF traces of aqueous $\mathrm{NaCl}$ and $\mathrm{KCl}$. For $\mathrm{NaCl}$ two records are reported to emphasize the metastabile condition of the supersaturation region (see text). 
This procedure therefore allowed evaluation of the solubility of the salts considered. The relevant values (see Table 1) are in good agreement with many literature reports [5, 34].

\begin{tabular}{|l|c|c|}
\hline solute & $\begin{array}{c}\text { Molal } \\
\text { Solubility } \\
\text { this work }\end{array}$ & $\begin{array}{c}\text { Molal } \\
\text { Solubility } \\
\text { Literature }\end{array}$ \\
\hline $\mathrm{NaCl}$ & $6.33 \pm 0.3$ & $6.1[5,35]$ \\
\hline $\mathrm{KCl}$ & $4.51 \pm 0.3$ & $4.5[5,35]$ \\
\hline $\mathrm{KNO}_{3}$ & $3.56 \pm 0.2$ & $3.5[5]$ \\
\hline
\end{tabular}

Table 1: Salt solubility at $25^{\circ} \mathrm{C}$ in ( $\mathrm{mol} / \mathrm{kg}$ water) units.

When a saturated salt solution undergoes the Knudsen dehydration, a simultaneous precipitation of solute takes place. This event does not produce any extra contribution to the mass loss rate, which is still related only to the release of water, but affects the overall heat flow, as the precipitation of the solute implies an exothermic contribution.

The $D T G$ and the $H F$ traces relevant to the saturated salt solutions can therefore be easily intepreted reminding the actually measured quantities. The $D T G$ trace reflects the mass loss rate and is therefore related only to the release of water. The $H F$ trace reflects the sum of two contributions, namely, water vaporization and salt crystallization, which have opposite signs. The corresponding treatment of the experimental trace therefore has to be performed accordingly.

Since $H F$ and $D T G$ are in $\mathrm{mW}$ and $\mathrm{mg} \mathrm{s}^{-1}$ units, respectively, the $(H F / D T G)_{\text {sub-sat }}$ ratio directly gives the vaporization enthalpy of water $\Delta_{\mathrm{vap}} h$ in $\mathrm{Jg}^{-1}$ units, in the sub-saturation regime,

$$
\Delta_{v a p} h=\left(\frac{H F}{D T G}\right)_{s u b-s a t}
$$

In the saturation regime the mass ratio between the aqueous solute and the water mass is constant and corresponds to the solubility, $s=m_{s} / m_{W}$. For this reason the salt precipitation rate $\left(\mathrm{d} m_{\mathrm{s}} / \mathrm{d} t\right)_{\text {sat }}$ is related to that of the simultaneous release of water, $\left(\mathrm{d} m_{\mathrm{W}} / \mathrm{d} t\right)_{\text {sat }}$ that correspond to the $D T G_{\text {sat }}$ signal, namely,

$$
\left(\frac{d m_{s}}{d t}\right)_{s a t}=s \times\left(\frac{d m_{W}}{d t}\right)_{s a t}=s \times D T G_{s a t}
$$

The corresponding thermal effetct, $H F_{\text {sat, }}$ includes both the vaporization of water and the salt crystallization contributions, namely, 


$$
H F_{s a t}=\left(D T G_{s a t} \times \Delta_{v a p} h\right)+\left(s \times D T G_{s a t} \times \Delta_{c r y s t} h\right)
$$

where $\Delta_{\text {vap }} h$, and $\Delta_{\text {cryst }} h$ stand for the relevant enthalpy drops in $\mathrm{Jg}^{-1}$ units. Accordingly,

$$
\Delta_{c r y s t} h=\frac{(H F / D T G)_{s a t}-(H F / D T G)_{\text {sub-sat }}}{s} \mathrm{~J} / \mathrm{g}_{\text {solute }}
$$

This quantity however could not be reliably evaluated because of the overwhelming effect of water vaporization during the dehydration of saturated salt solutions, which makes the difference at the numerator of the above expression close to zero.

Unfortunately the experimental evidence collected from the aqueous solutions of highly soluble sugars did not allow the same data treatment. None of these solutes showed a DTG saturation trend. The release of water occurred smoothly from the starting subsaturation condition toward the full dry matter with no apparent discontinuities (Figure 6). The simultaneous record of the heat flux remained parallel to the $D T G$ trace, namely it did not show any exothermic spike. This suggests that these sugar solutions tend to form homogeneous amorphous systems, where water and sugar coexist in the same phase, rather than undergo solute precipitation once the solubility threshold is trespassed. Such a behaviour is probably related to the large viscosity of concentrated sugar solutions that hinders the growth of the crystal phase(s) of the sugar.

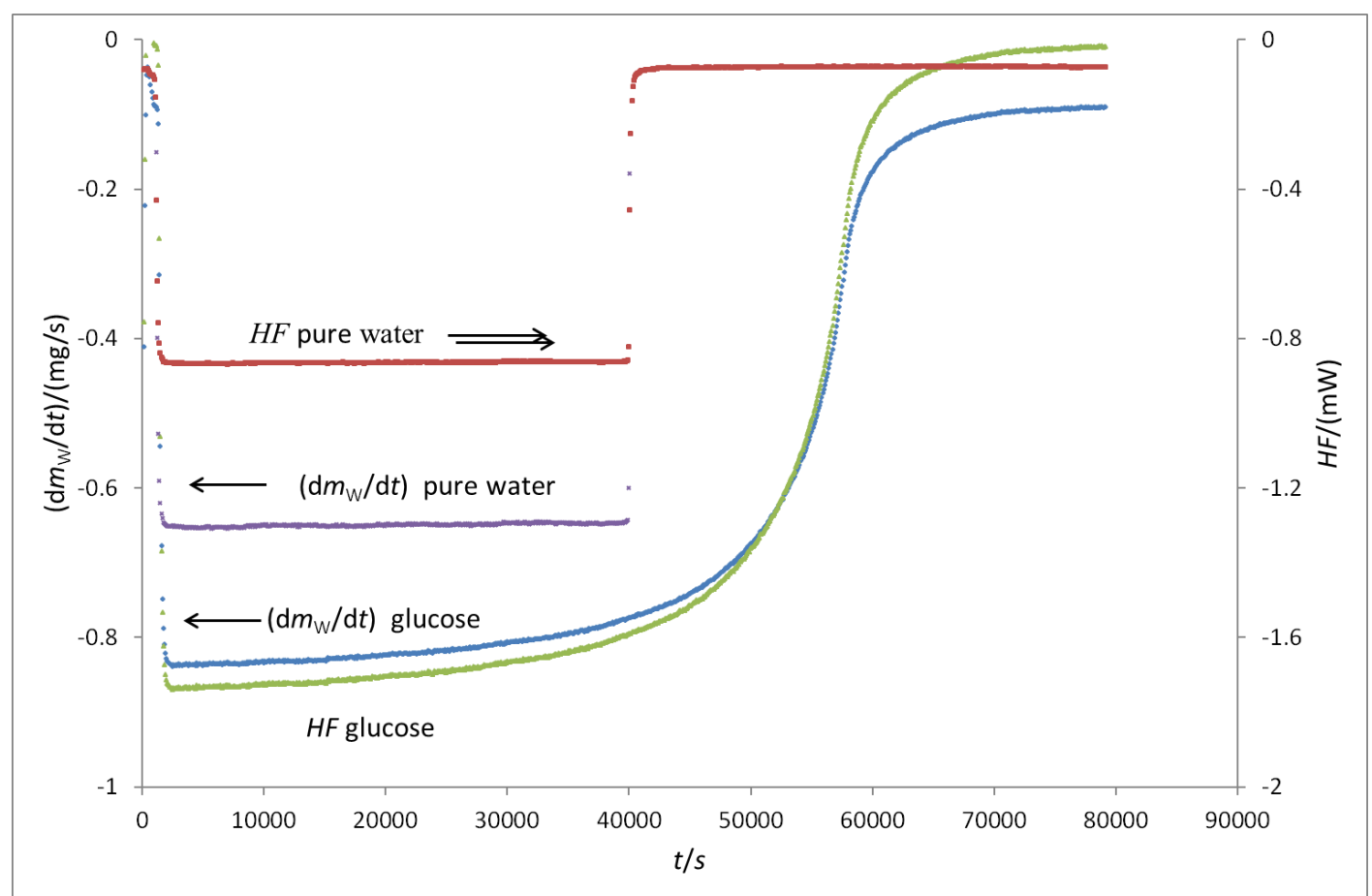

Figure 6. HF and DTG traces collected from glucose compared to those of pure water at $25^{\circ} \mathrm{C}$. 
For this reason the late phase of the DTG trace deals with a system that remains far from a true thermodynamic equilibrium. The early phase of the desorption is instead reliable and allows a correct thermodynamic analysis of the data.

\section{Thermodynamic activity}

\section{Aqueous solutions of electrolytes}

As mentioned above, the Knudsen $D T G$ trace recorded from a subsaturated solution is a bending curve which is easy to fit with a simple polynomial equation $F(t)$. Dividing $F(t)$ by the averaged DTG trace collected from pure water sample (in the same Knudsen-like cell, vacuum conditions and temperature), the corresponding trend of water activity, $a_{\mathrm{W}}(t)$, is obtained (Figure 7). The function $a_{\mathrm{W}}(t)$ can be easily transformed into the function $a_{\mathrm{W}}(m)$, where $m$ stands for molality of the solute, since the mass of water, $m_{\mathrm{W}}$, is simply given by the difference $\left[m_{\mathrm{W}}(0)-\Delta m_{\mathrm{W}}\right]\left(\Delta m_{\mathrm{W}}\right.$ being drawn from the TG trace. See Figure 2), while the solute mass, $m_{\mathrm{S}}$, is the same as for $t=0$ (Figure 7).
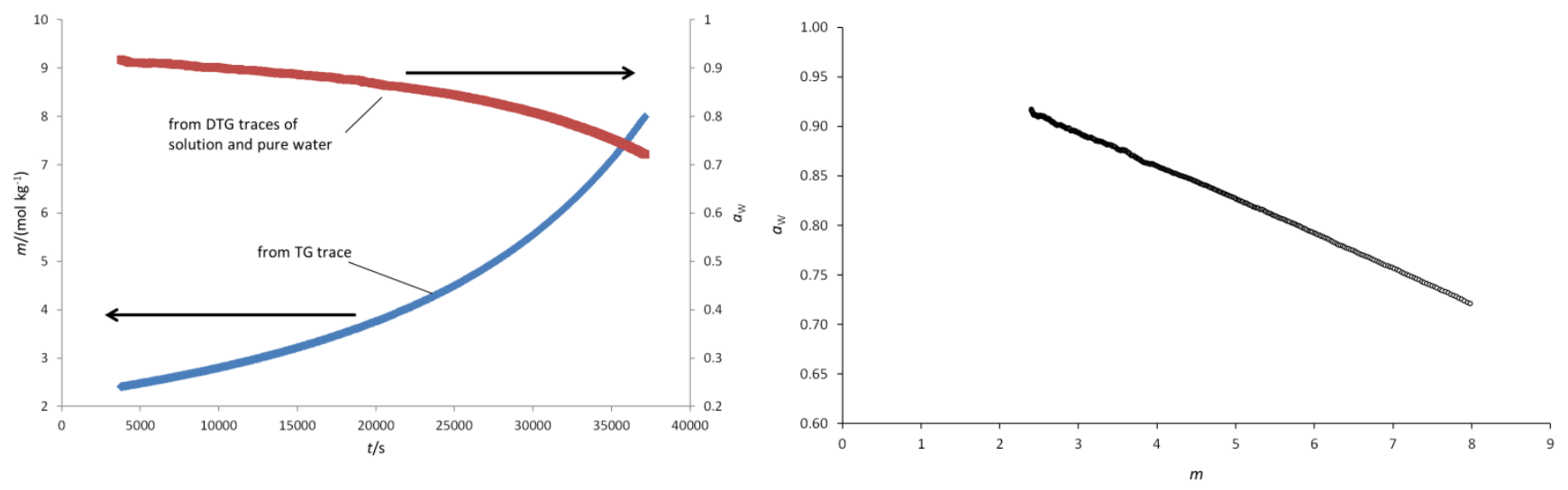

Figure 7. Data treatment to pass from the isothermal Knudsen DTG record to the $a_{\mathrm{W}}$ trend at various solute molality. The figure reports the case of aqueous $\mathrm{NaCl}$ at $25^{\circ} \mathrm{C}$.

The function $a_{\mathrm{W}}(m)$ corresponds to the trend of a classical set of isopiestic data and allows the traditional treatment based on the Gibbs-Duhem relationship to evaluate the thermodynamic activity of the solute, $a_{\mathrm{S}}$, its activity coefficient, $\gamma_{\mathrm{S}}$, and the related practical osmotic coefficient, $\Phi$.

with $\alpha=1$ and 2 for non-electrolytes and 1-1 strong electrolyte, respectively, and $M=1810^{-3} \mathrm{~kg}$ $\mathrm{mol}^{-1}$. Integration of equation (4) leads to an expression for $\ln a_{\mathrm{W}}$, 


$$
\begin{aligned}
-\ln a_{W} & =\alpha M m+\int m \mathrm{~d} \ln \gamma_{S}=\alpha M m+F(m)= \\
& =\alpha M m \times \Phi(m)
\end{aligned}
$$

with $F(m=0)=0$ and $F^{\prime}(m=0)=0$, that meets the expectation of the Raoult law for $m \rightarrow 0$, namely,

$$
\left(\frac{-d \ln a_{W}}{d m}\right)_{m \rightarrow 0}=\alpha M
$$

As an example, the cases of $\mathrm{NaCl}$ and glucose, that represent the behavior of 1-1 strong electrolytes and non-electrolytes, respectively, are reported in Figure 8.

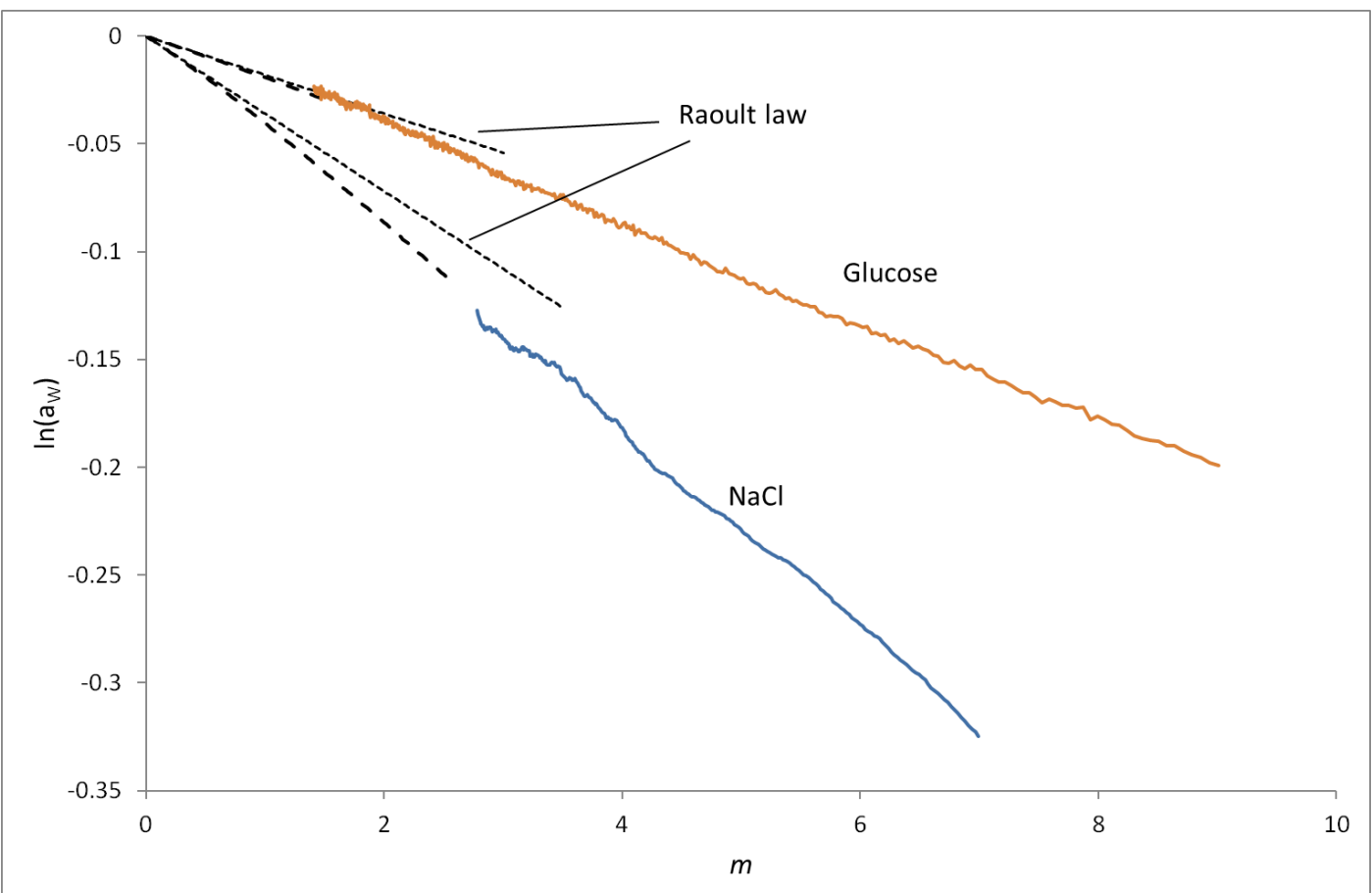

Figure 8. Dashed lines correspond to polynomial fits; dotted lines correspond to the Raoult trend. Heavy lines directly come from the experimental $a_{W}$ data obtained with Knudsen TG experiments.

The function $F(m)$ can be directly drawn from the experimental data collected in a single Knudsen TG run, namely,

$$
F(m)=-\left(\ln a_{w}+\alpha M m\right)
$$

and can be represented with any empirical fit that allows evaluation of its derivative $F^{\prime}(m)$. The reliability of such fits is that they reflect the continuous Knudsen TG record. Equation (4) allows to draw expressions for the activity coefficient and the practical osmotic coefficient,

$$
\mathrm{d} \ln \gamma_{s}=\frac{F^{\prime}(m)}{\alpha M m} \mathrm{~d} m
$$

and 
The functions $F(m)$ and $\Phi(m)$ obtained from the experimental record of the the Knudsen TG trace are simple empirical fits that may not be compared with the extended expressions of the Debye-Hückel law for strong electrolytes [3, 4, 9] and those relevant to neutral solutes [2, 6], but allow numerical or analytical integration to obtain the trend of $\ln \gamma_{S}(m)$. For example, integration of equation (6) by parts, gives

$$
\ln \gamma_{s}=\frac{1}{\alpha M}\left[\frac{F(m)}{m}+\int \frac{F(m)}{m^{2}} d m\right]+\text { const }
$$

Alternatively, one may use the expression

that allows a numerical integration.

As for the $a_{\mathrm{W}}$-vs- $m$ trends, the agreement between the result of this work and the literature data was satisfactory for the aqueous electrolytes considered (figure 9) and for maltose and glucose (Figure 10), while larger discrepancies were found for large molalities of sucrose and fructose (see Figure 10) that are the most soluble sugars and therefore more inclined to produce aqueous solutions with a large viscosity.
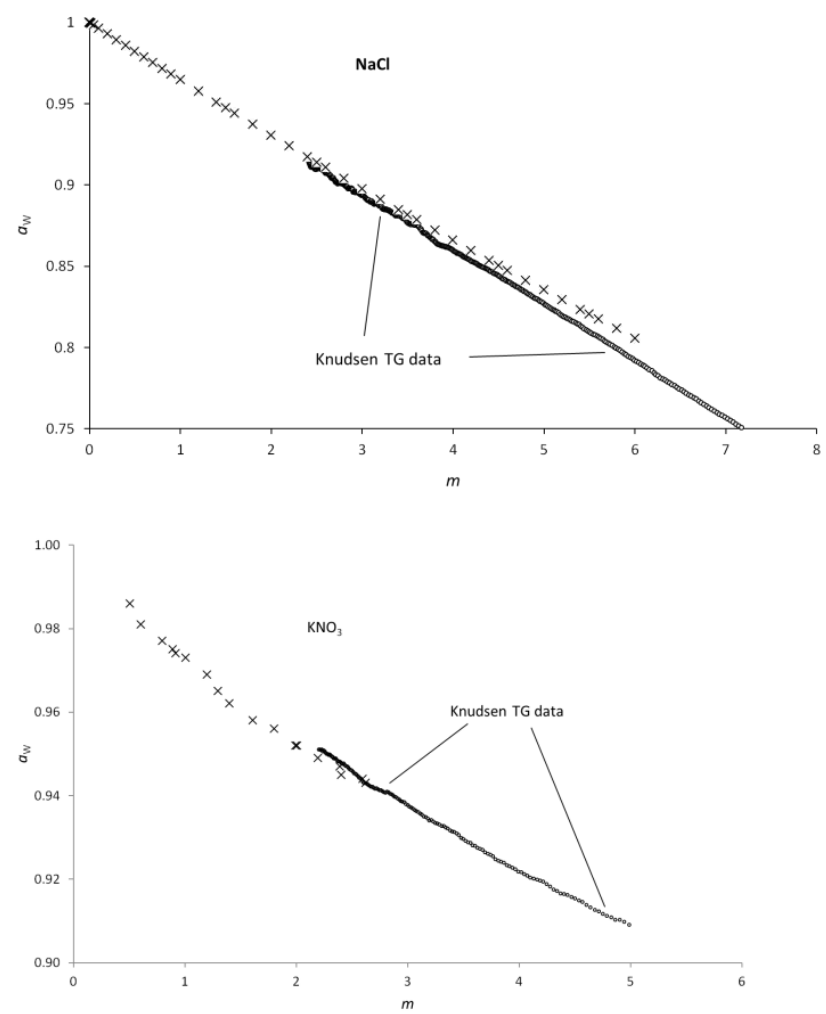

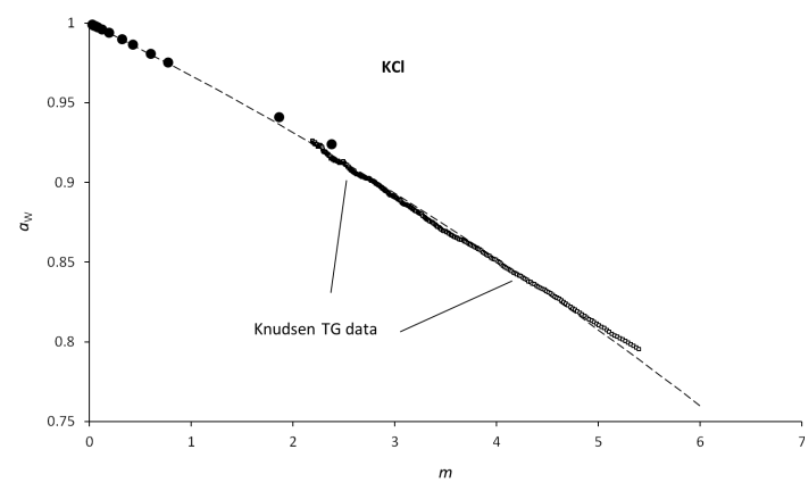

Figure 9. Water activity as a function of solute molality for $\mathrm{NaCl}, \mathrm{KCl}$ and $\mathrm{KNO}_{3}$. The data of the present work are directly drawn from KnudsenDTG traces. Literature data: $\mathrm{NaCl}$ [35] , $\mathrm{KCl}$ [36], and $\mathrm{KNO}_{3}$ [5].

This may produce concentration gradients across the Knudsen cell that, in the present configuration, does not allow stirring. Nonetheless, for a given solute molality, the $a_{\mathrm{W}}$ values obtained in the present work are larger than those reported in the literature: this means that they 
should be closer to the "true" values, since the data treatment (see Materials and Methods) took into
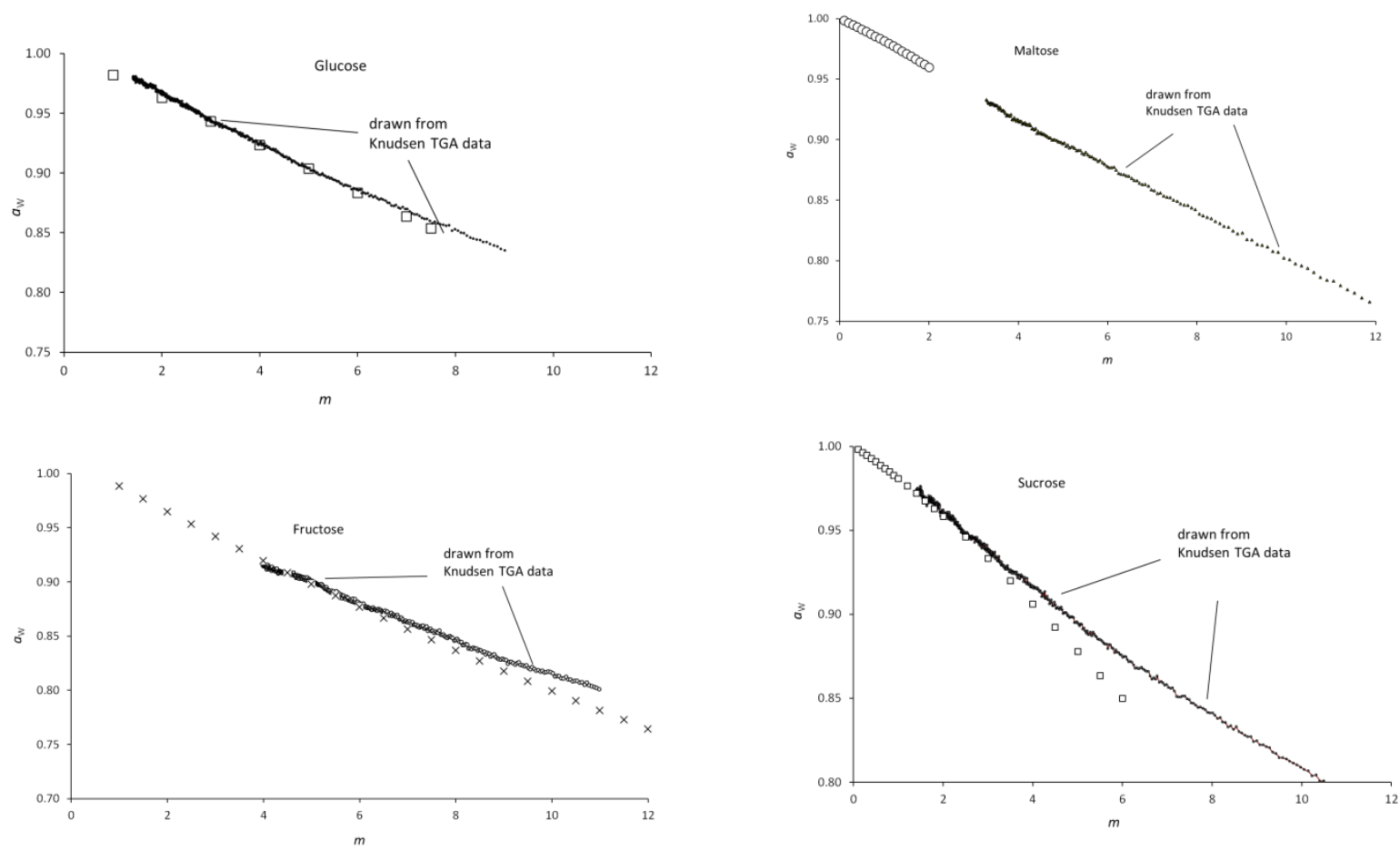

Figure 10: Water activity as a function of solute molality for glucose, fructose, sucrose and maltose. The data of the present work are directly drawn from Knudsen DTG traces. Literature data: maltose [37]; fructose [38]; glucose and sucrose [6, 39].

\section{CONCLUSIONS}

The use of isothermal TG with Knudsen-like cells allows determination of the thermodynamic activity of water, $a_{\mathrm{w}}$. The method is alternative to the classical isopiestic approach and offers the advantage of a continuous record on increasing the solute concentration. These data can be directly treated according to the classical thermodynamic relationships drawn from the Gibbs-Duhem expression to evaluate the activity and osmotic coefficient of the aqueous solutions of electrolytes and non-electrolytes. Deviations from the expected trends can be observed when the viscosity of the systems does not allow an isotropic concentration of the solute as in the case of sugars with a very large solubility. Such a mismatch may be reduced by slowing the dehydration rate with use of a narrower Knudsen orifice, or, as in the present work, correcting the experimental $a_{\mathrm{W}}$ with a calibration curve. Because of the simple requirements of the Knudsen TGA approach, this method can be extended to the study of non-aqueous systems. This is indeed the intention of the authors for a future work. 


\section{REFERENCES}

1. Debye P. and Hückel E., Zur Theorie der Elektrolyte. I. Gefrierpunktserniedrigung und verwandte Erscheinungen (The theory of electrolytes. I. Lowering of freezing point and related phenomena)., Physik Z., 24 (1923) 185-206.

2. Scatchard G., Hamer W.J. and Wood S.E., Isotonic solutions. I. The chemical potential of water in aqueous solutions of sodium chloride, potassium chloride, sulfuric acid, sucrose, urea and glycerol, JACS, 60 (1938) 3061-3070.

3. Guggenheim E. A., "Applications of Statistical Mechanics, Clarendon Press, Oxford, (1966) 166-170;

4. Pitzer K.S., Thermodynamics of electrolytes. 1. Theoretical basis and general equation. J. Phys. Chem., 1973, 77, 268-277.

5. Hamer, W. J.; Wu, Y. C. Osmotic Coefficients and Mean Activity Coefficients of UniUnivalent Electrolytes in Waters at $25^{\circ} \mathrm{C}$. J. Phys. Chem. Ref. Data, 1 (1972) 1047-1099;

6. Robinson R.A. and Stokes R.H., Activity coefficients in aqueous solution of sucrose, mannitol and their mixtures at $25^{\circ} \mathrm{C}$, J. Phys. Chem., 65 (1961) 1954-1958

7. Goldberg R.N., Evaluated activity and osmotic coefficients for aqueous solutions: thirty-six uni-bivalent electrolyte, J. Phys. Chem. Data, 10 (1981) 671- 764.

8. Goldberg R.N. and Tewari Y.B., Thermodynamic and transport properties of carbohydrates and their monophosphates: the pentoses and hexoses. J. Phys. Chem. Ref. Data, 18 (1989) 809880.

9. Pan C., Activity and osmotic coefficients in dilute aqueous solutions of uni-univalent electrolytes at $25^{\circ} \mathrm{C}, \mathrm{J}$. Chem. Eng. Data, 26 (1981) 183-184.

10. Malatesta F., Fagiolini C. and Franceschi R., Activity coefficients in mixed electrolyte solutions, Phys. Chem. Chem. Phys., 6 (2004) 124-138.

11. Pitzer K.S. and Simonson J.M., Ion Pairing in a System Continuously Miscible from the Fused Salt to Dilute Solution, JACS, 106 (1984) 1973-1977.

12. Partanen J.I., Salmimies R.K., Partanen L.J. and Louhi-Kultanen M., Prediction of activity coefficients for uni-univalent electrolytes in pure aqueous solutions,Chem. Eng. Technol., 5 (2010) 730-742.

13. Blandamer M.J., Engberts B.F.N., Gleeson P.T.and Reis J.C., Activity of water in aqueous systems; a frequently neglected property, Chem. Soc. Rev., 34 (2005) 440-458.

14. Tani A. and Henderson D., A cluster theory for electrolytes, J. Chem. Phys., 79 (1983) 23902394.

15. Peres A. M. and Macedo E.A., Thermodynamic properties of sugars in aqueous solutions: correlation and prediction using a modified UNIQUAC model, Fluid Phase Equilibria 123 (1996) 71-95

16. Bretti C., Foti C., Porcino N. and Sammartano S., SIT parameters for 1:1 electrolytes and correlation with Pitzer coefficients, J. Solution Chem., 35 (2006) 1401-1415.

17. Ge X. and Wang X., A Simple Two-Parameter Correlation Model for Aqueous Electrolyte Solutions across a Wide Range of Temperatures, J. Chem. Eng. Data, 54 (2009) 179-186.

18. Sereno A.M., Hubinger M.D., Comesaña and Correa A., Prediction of water activity of osmotic solutions, J. Food Eng., 49 (2001) 103-104.

19. Kuramochi H., Noritomi H., Hoshino D. and Nagahama K., Representation of activity coefficients of fundamental biochemicals in water by the UNIFAC model, Fluid Phase Equilibria, 130 (1997) 117-132.

20. Lee S.L., Denedetti P. and Errington J.R., A computational study of hydration, solution structure and dynamics in dilute carbohydrate solutions, J. Chem. Phys., 122 (2005) 204511-1 204511-10. 
21. Kalyuzhni Y.V., Vlachy V. and Dill K.A., Aqueous alkali halise solutions: can osmotic coefficients be explained on the basis of the ionic sizes alone?, Phys. Chem.Chem.Phys., 12 (2010) 6260-6266.

22. Scatchard G., Concentrated solutions of strong electrolytes, Chem. Rev., 19 (1936) 309-327.

23. Ananthaswamy J. and Atkinson G., Thermodynamics of concentrated electrolyte mixtures. 4. Pitzer-Debye-Hückel limiting slopes for water from 0 to $100^{\circ} \mathrm{C}$ and from 1 atm to $1 \mathrm{kbar}, \mathrm{J}$. Chem. Eng. Data, 29 (1984) 81-87.

24. Chirife J. and del Pilar Buera M., water activity, water glass dynamics and the control of microbioloigal growth in foods, Crit. Rev. Food Sci. Nutr. 36 (1996) 465-513.

25. Barbosa-Cànovas G.V., Fontana Jr, A.J., Schmidt S.J., Labuza T.P., Water Activity in Foods: Fundamentals and Applications. 2007, IFT Press Series, Blackwell Publ.

26. Roos H.Y., Phase Transitions in Foods. 1995, Acad. Press Inc. San Diego, California.

27. Schiraldi A., Fessas D. and Signorelli M., Water Activity in Biological Systems - A Review, Polish J. Food Nutr. Sci., 62 (2012) 5-13.

28. Schiraldi A. and Fessas D., Classical and Knudsen thermogravimetry to check states and displacements of water in food systems, J. Therm. Anal. Cal., 71 (2003) 221-231.

29. Fessas D., Schiraldi A., Water properties in wheat flour dough II: classical and Knudsen thermogravimetry approach. Food Chem., 2005, 90, 61-68.

30. Pani P., Schiraldi A., Signorelli M., Fessas D., Thermodynamic approach to osmo-dehydration. Food Biophys., 2010, 5, 177-185.

31. Knudsen M.H.C., The Kinetic Theory of Gases, Methuen \& Co Publ. (London, 1934).

32. Ward J.W. and Mulford R.N.R., Study of some of the parameters affecting Knudsen Effusion. I. Experimental tests of validity of the cosine law as a function of cell and sample geometrics and materials. J. Chem.Phys., 47 (1967) 1710-1717.

33. Greenspan L., J. Res. Nat. Bureau of Standars-A, 81A (1) (1977) 89-96.

34. Guendouzi, M. E. I.; Dinane, A. Determination of Water Activities, Osmotic and Activity Coefficients in Aqueous Solutions Using the Hygrometric Method. J. Chem. Thermodyn. 2000, 32, 297-310.

35. Pitzer K. and Pelper J. C., Thermodynamic properties of aqueous sodium chloride solutions,J. Phys Chem. Ref. Data, 13 (1984) 1- 102.

36. Archer D. G., Thermodynamic Properties of the $\mathrm{KCl}+\mathrm{H}_{2} \mathrm{O}$ system, J. Phys Chem. Ref. Data, 28 (1999) 1- 16.

37. Miyajima K., Sawada M. and Nakagaki M., Studies on aqueous solutions of saccharides. II. Viscosity B-coefficients, apparent molar volume and activity coefficients of D-glucose, Maltose and maltotriose in aqueous solutions, Bull. Chem. Soc. Jpn, 56 (1983) 1954 - 1957.

38. Rüegg M., Blanc B., The Water Activity of Honey and Related Sugar Solutions, Leben. Wiss. Technol., 14 (1981) 1-6.

39. Stokes R.H. and Robinson R.A., Interactions in Aqueous Nonelectrolyte Solutions. I. Solute Solvent Equilibria, J. Phys. Chem., 70 (1966) 2126-31. 
Table1

\begin{tabular}{|l|c|c|}
\hline solute & $\begin{array}{c}\text { Molal } \\
\text { Solubility } \\
\text { this work }\end{array}$ & $\begin{array}{c}\text { Molal } \\
\text { Solubility } \\
\text { Literature }\end{array}$ \\
\hline $\mathrm{NaCl}$ & $6.33 \pm 0.3$ & $6.1[5,35]$ \\
\hline $\mathrm{KCl}$ & $4.51 \pm 0.3$ & $4.5[5,35]$ \\
\hline $\mathrm{KNO}_{3}$ & $3.56 \pm 0.2$ & $3.5[5]$ \\
\hline
\end{tabular}


Click here to download high resolution image

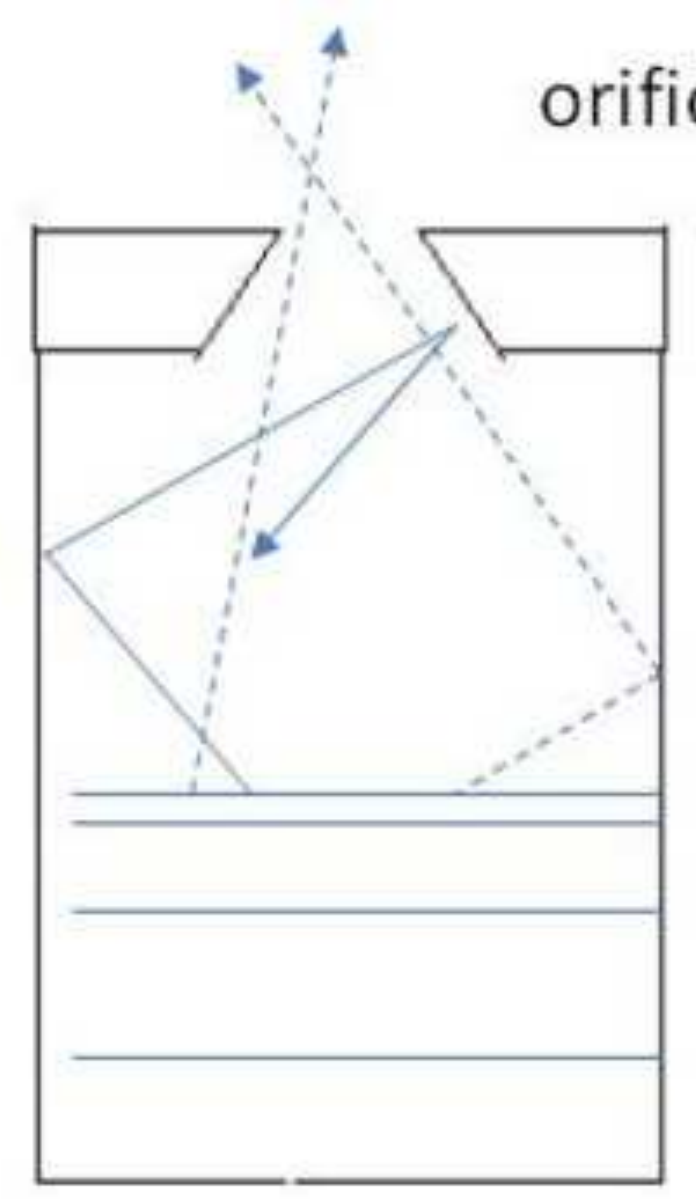

\title{
Cell cover
}

Head space

\author{
Liquid phase
}




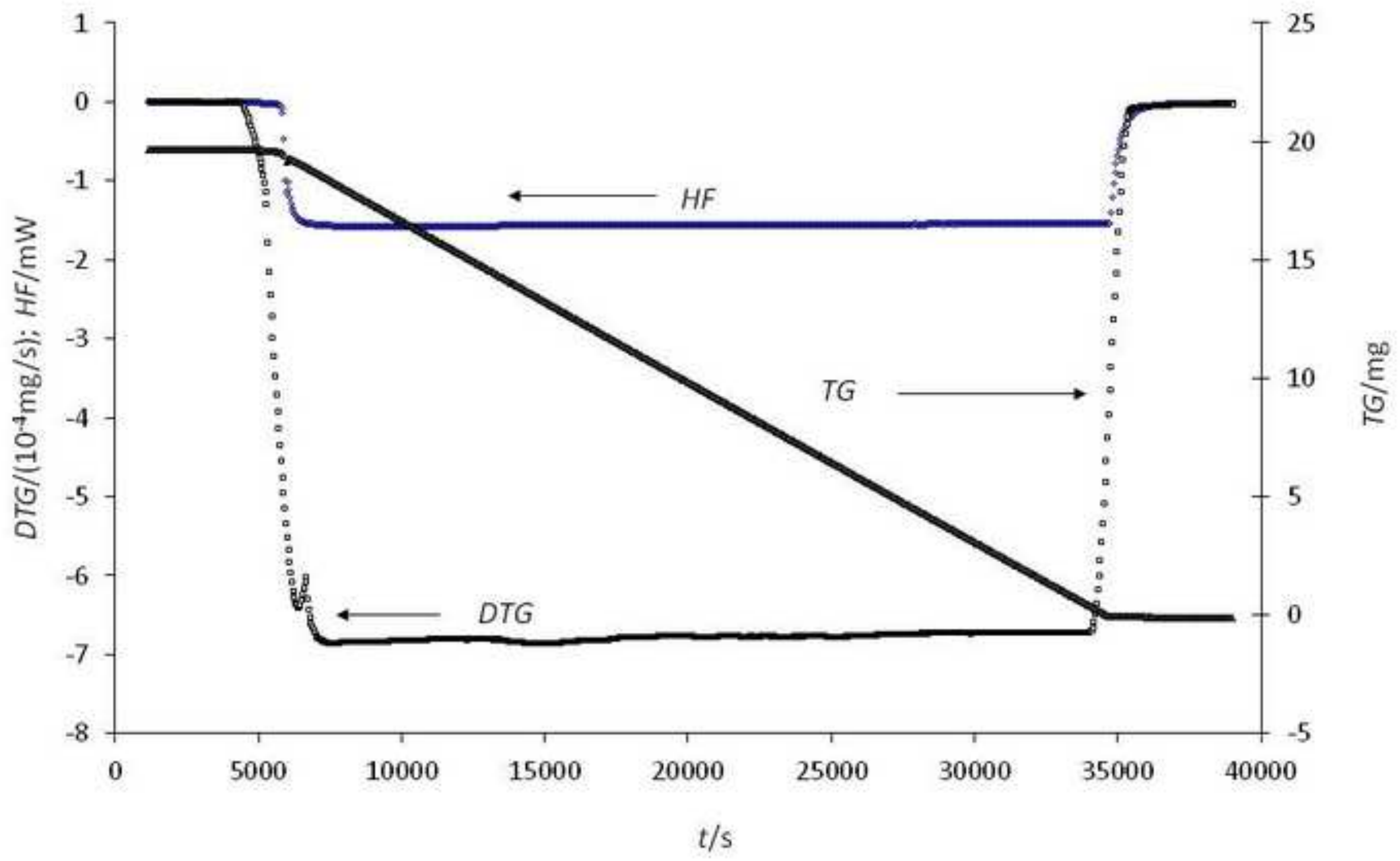


Click here to download high resolution image

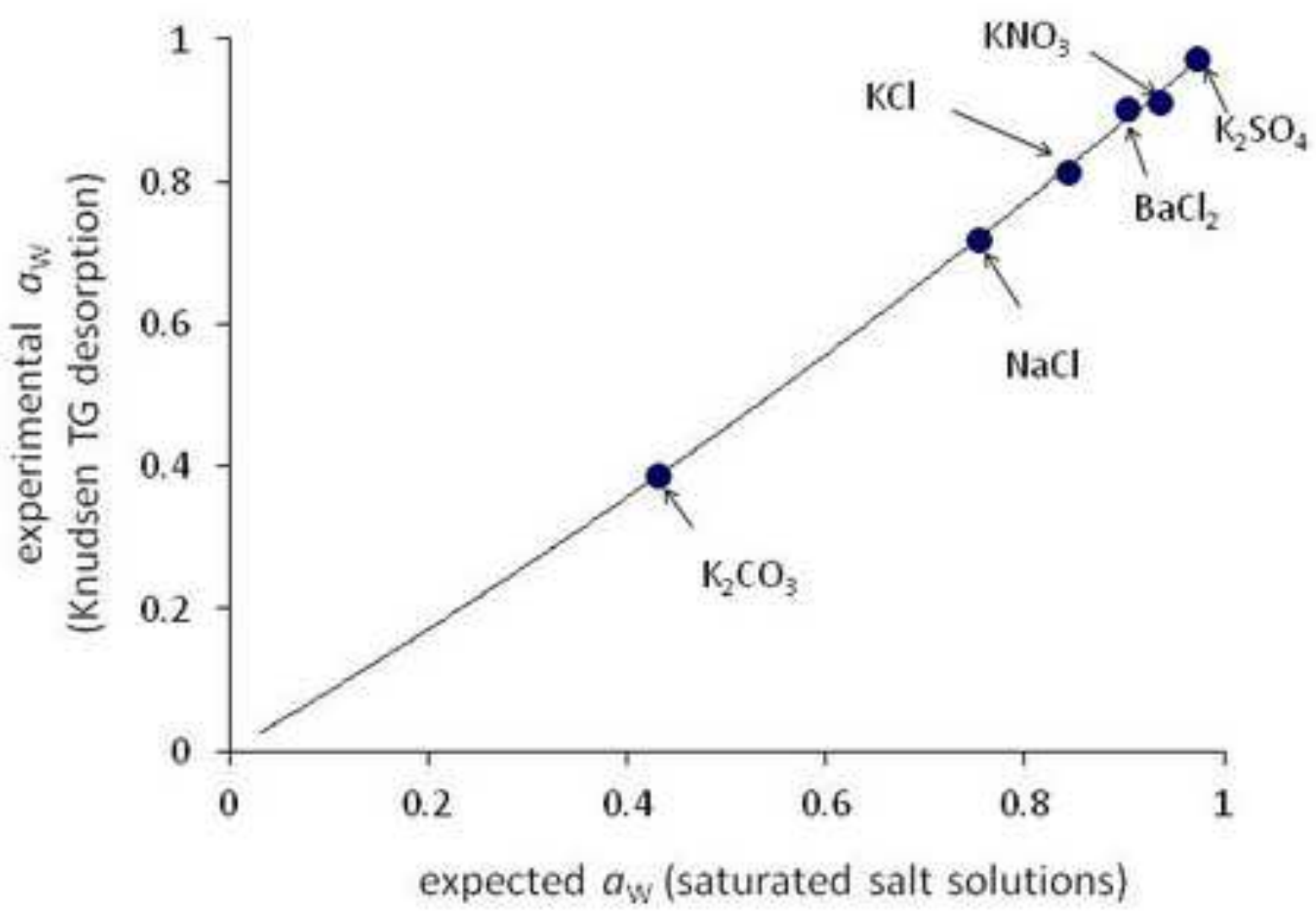


Click here to download high resolution image

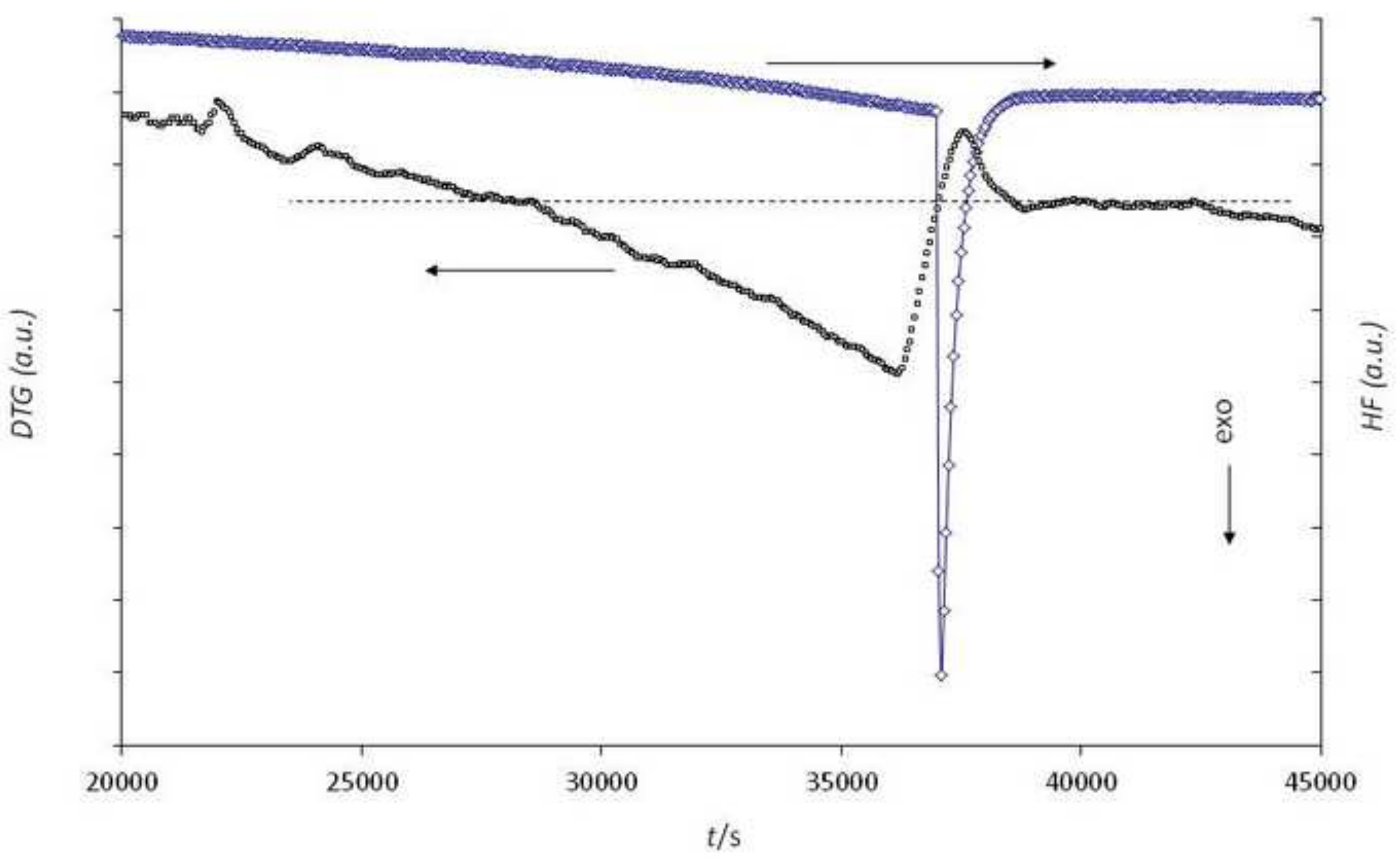


Click here to download high resolution image

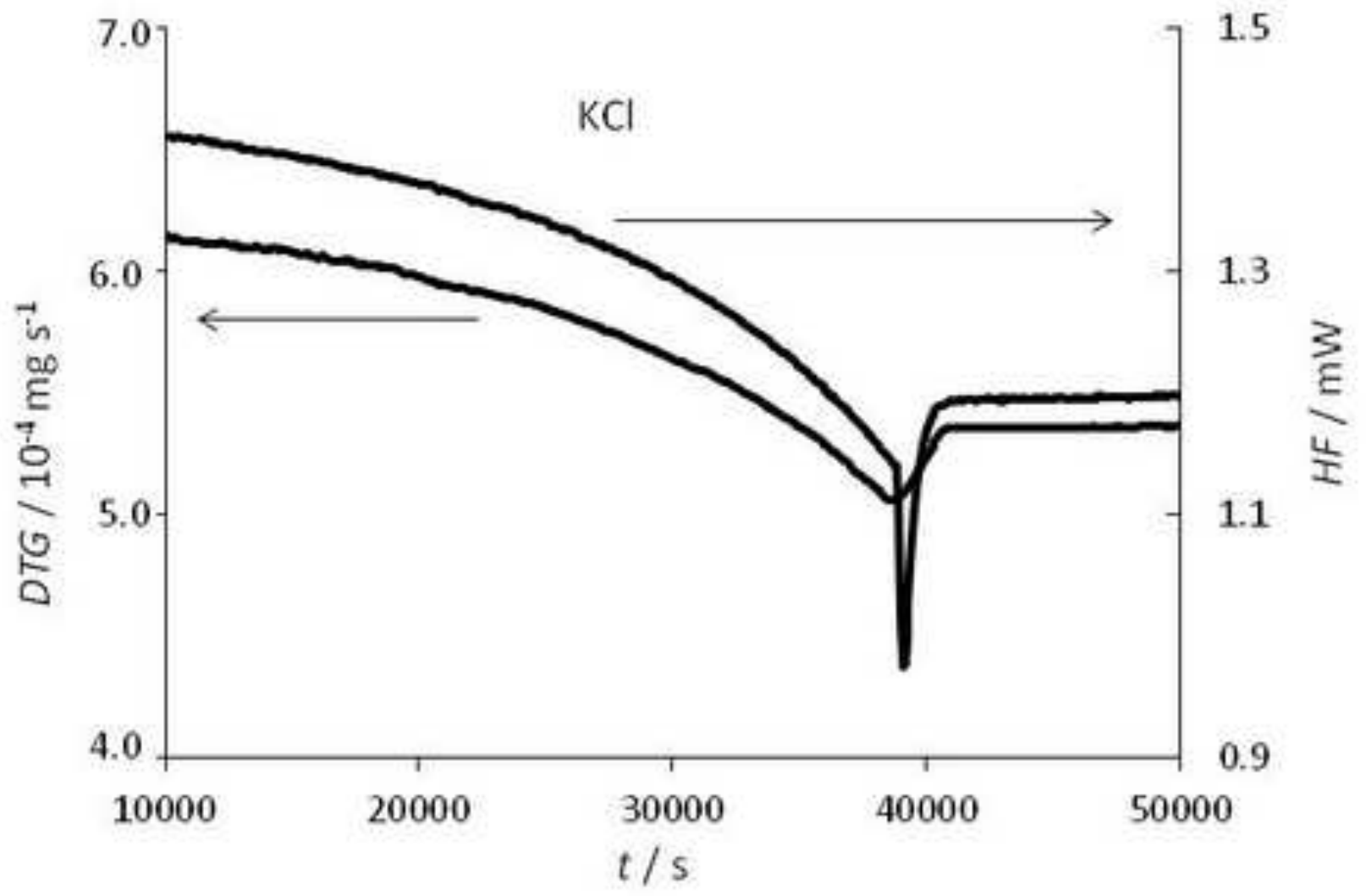


Click here to download high resolution image

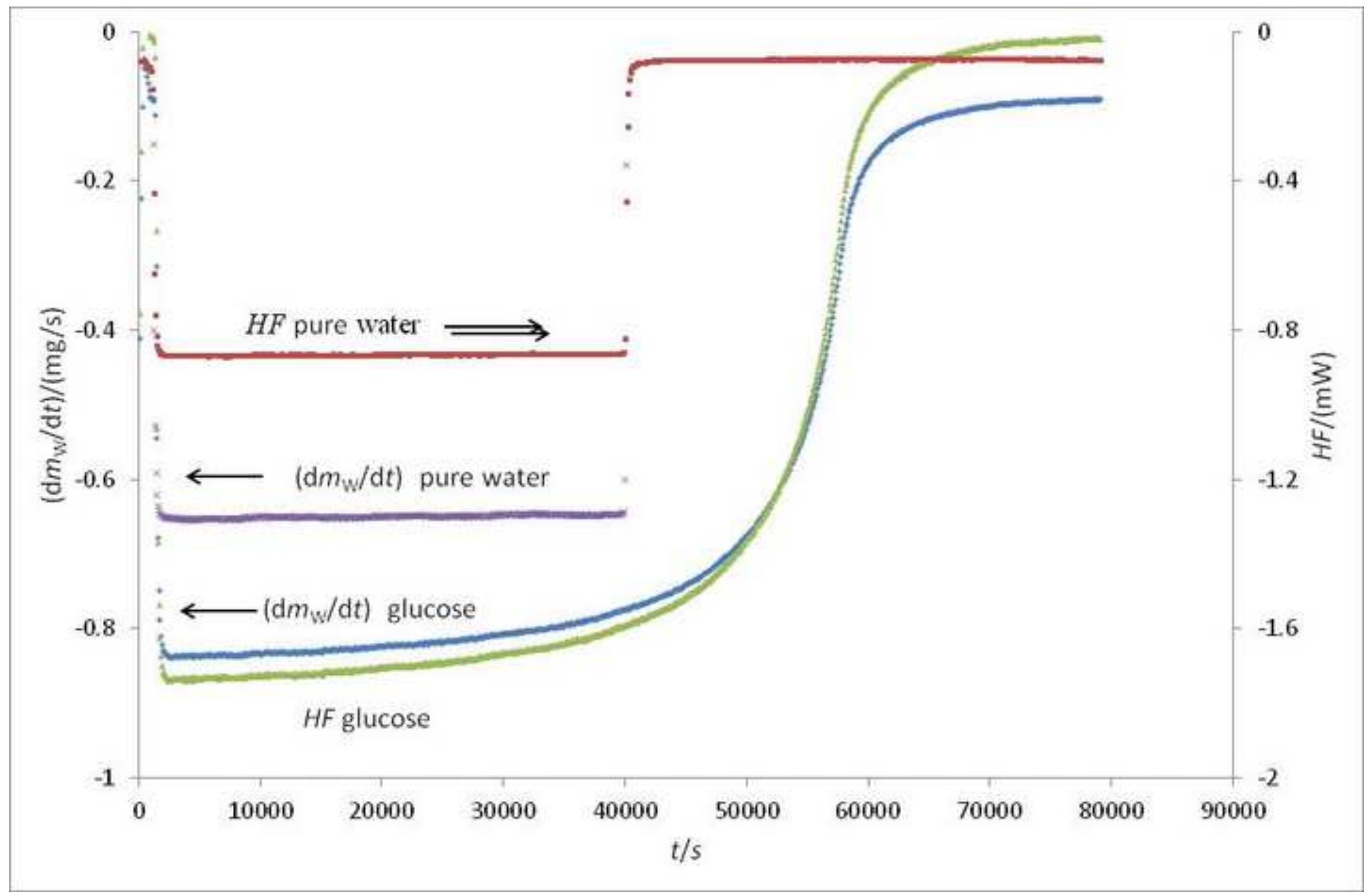




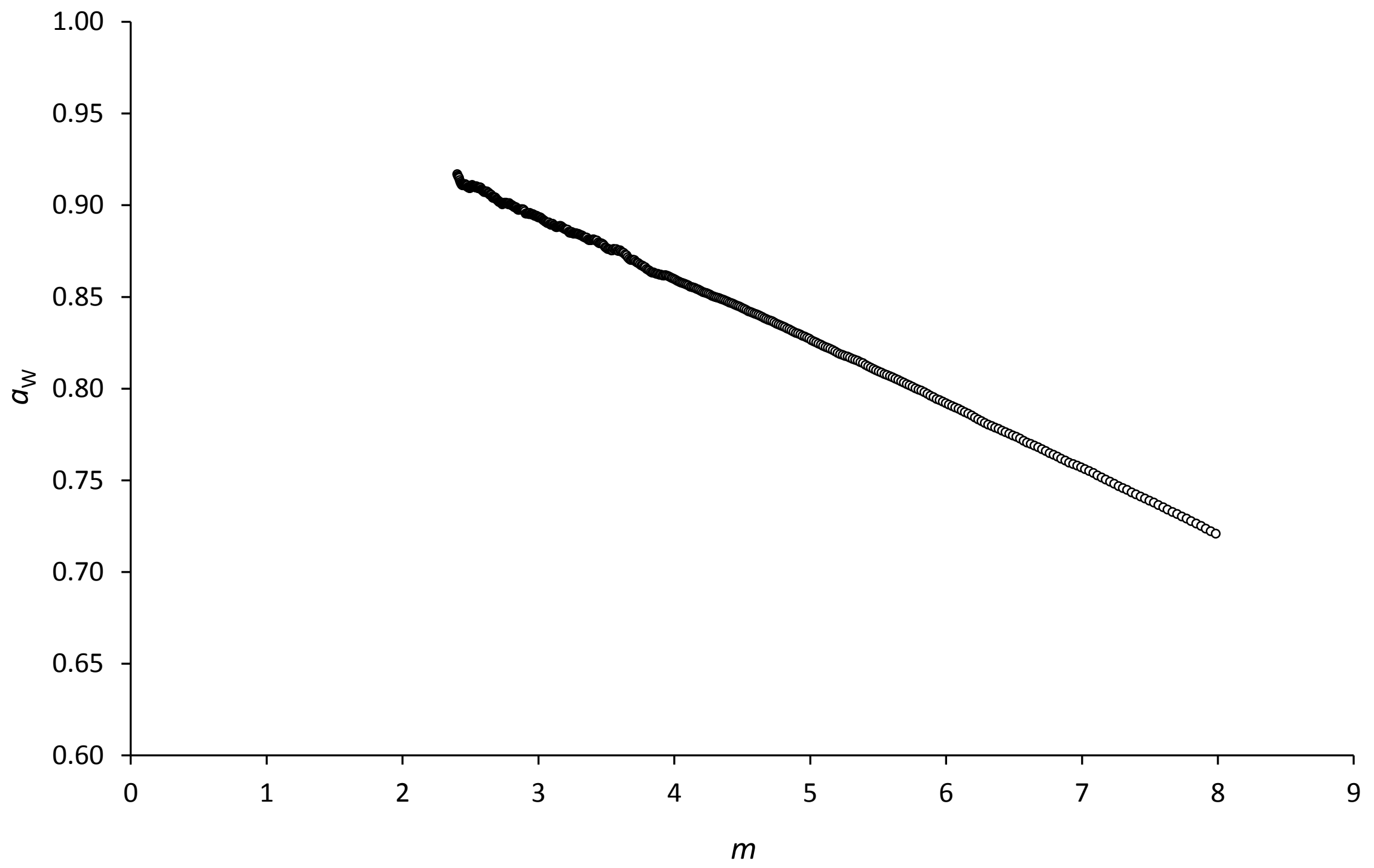




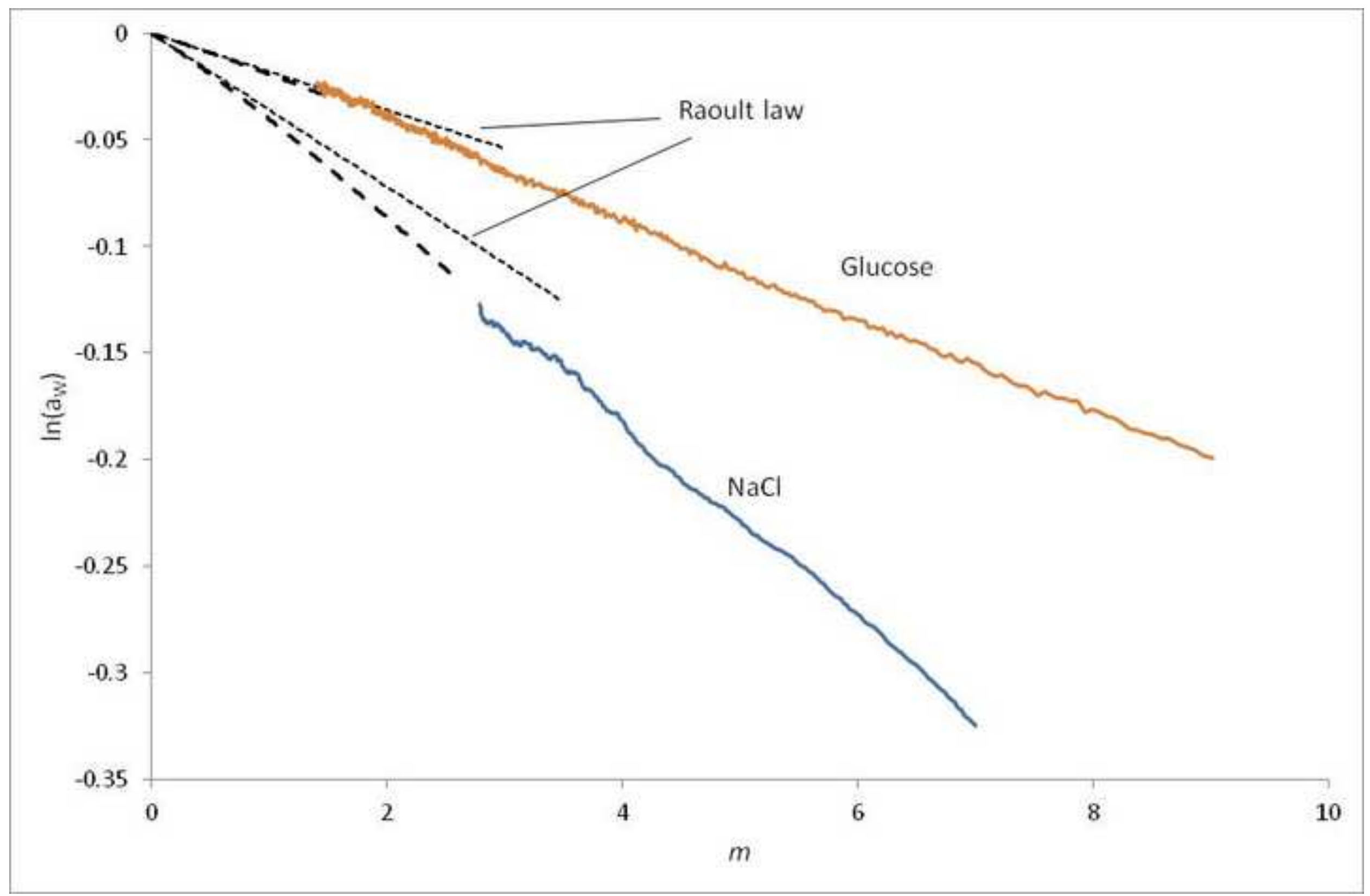


Click here to download high resolution image

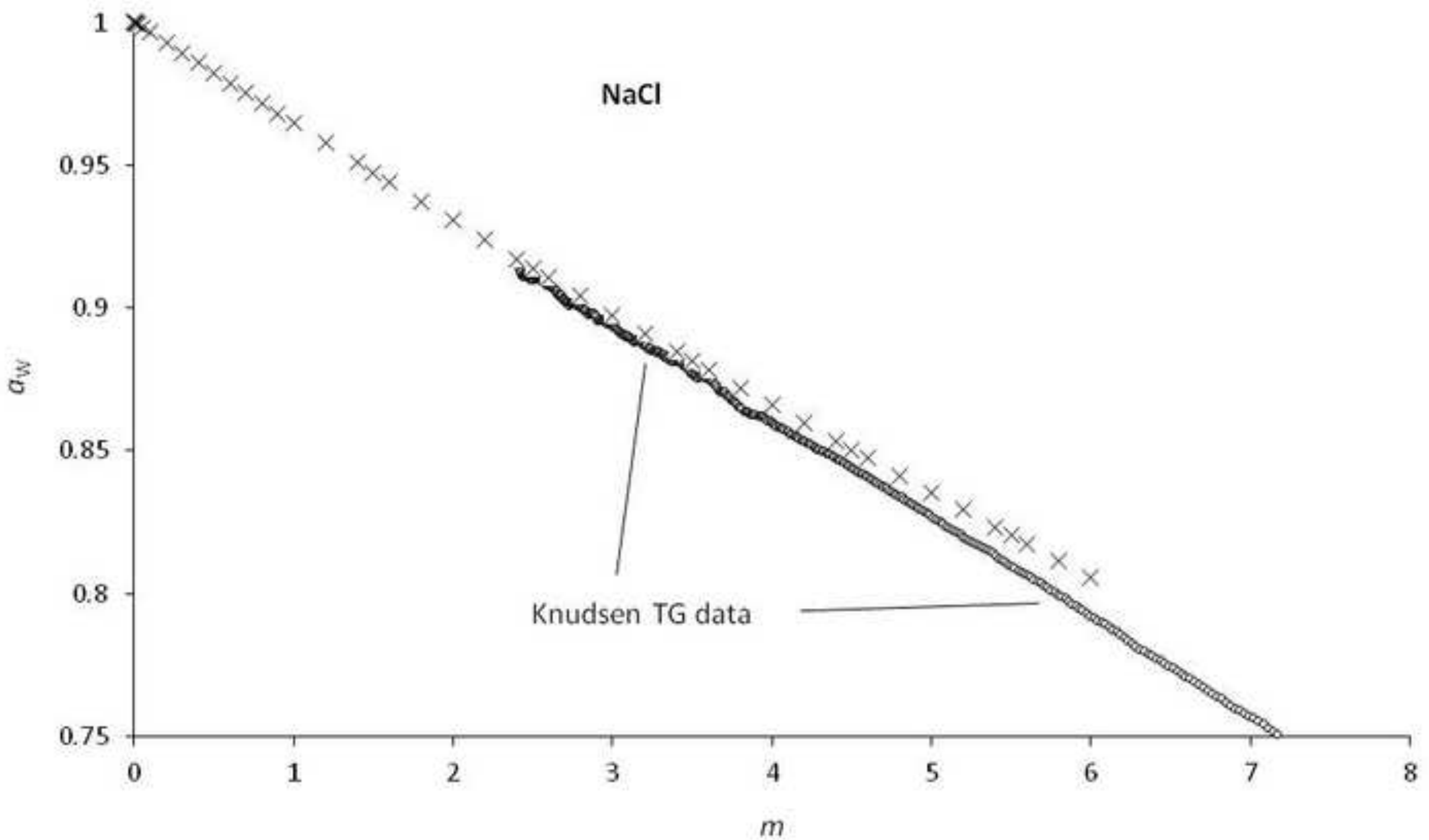


Click here to download high resolution image

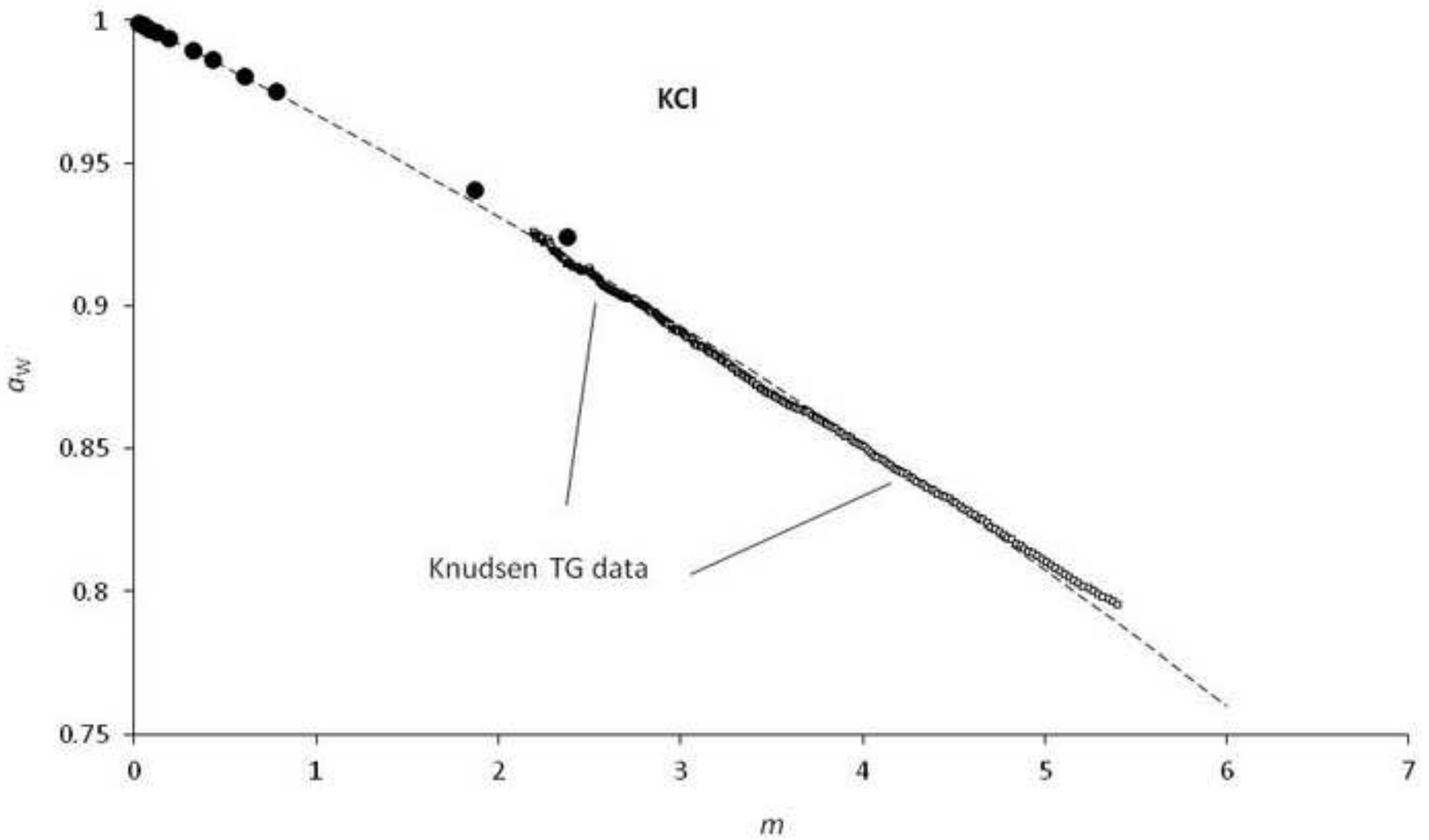


Click here to download high resolution image

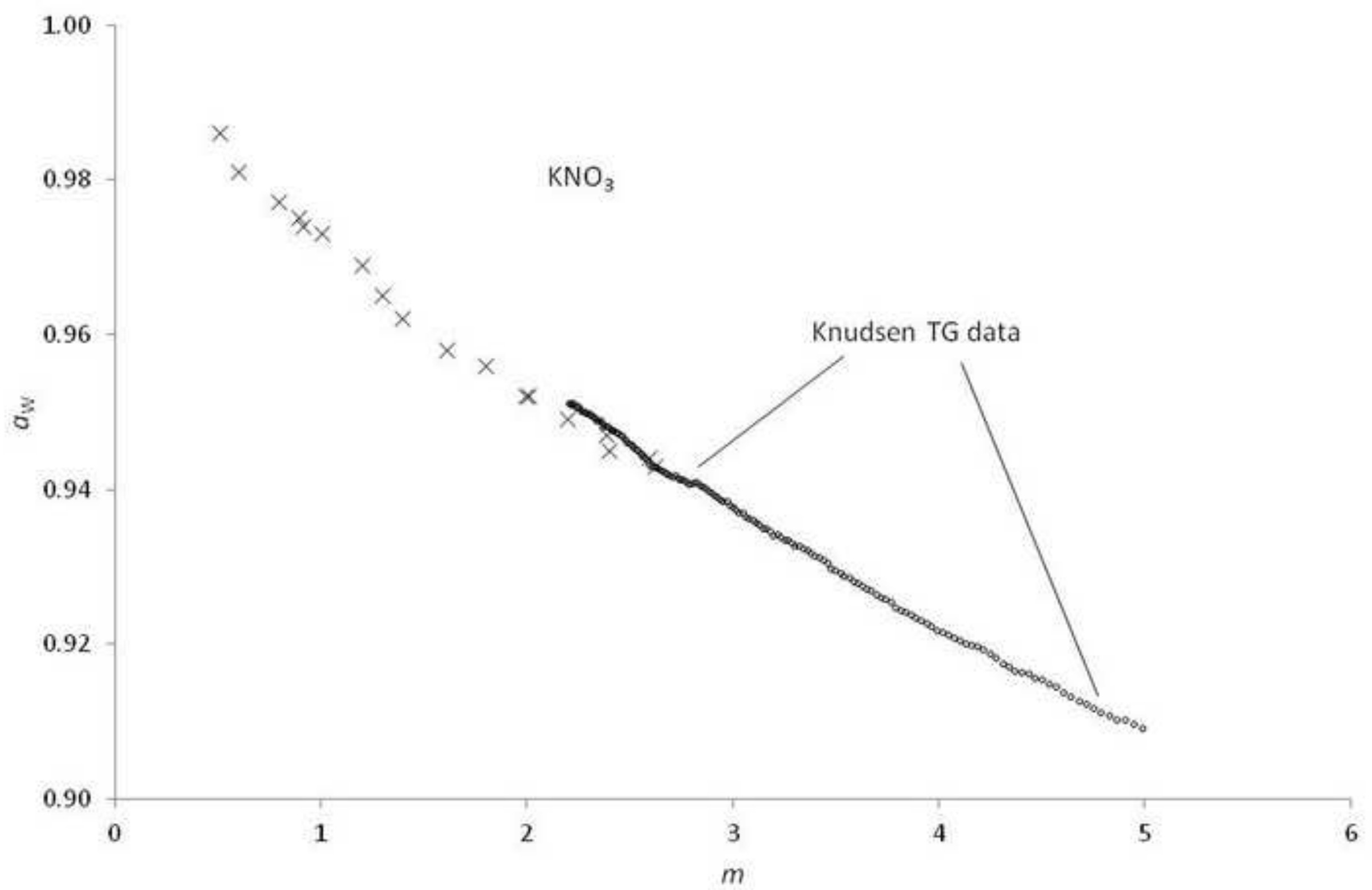


Click here to download high resolution image

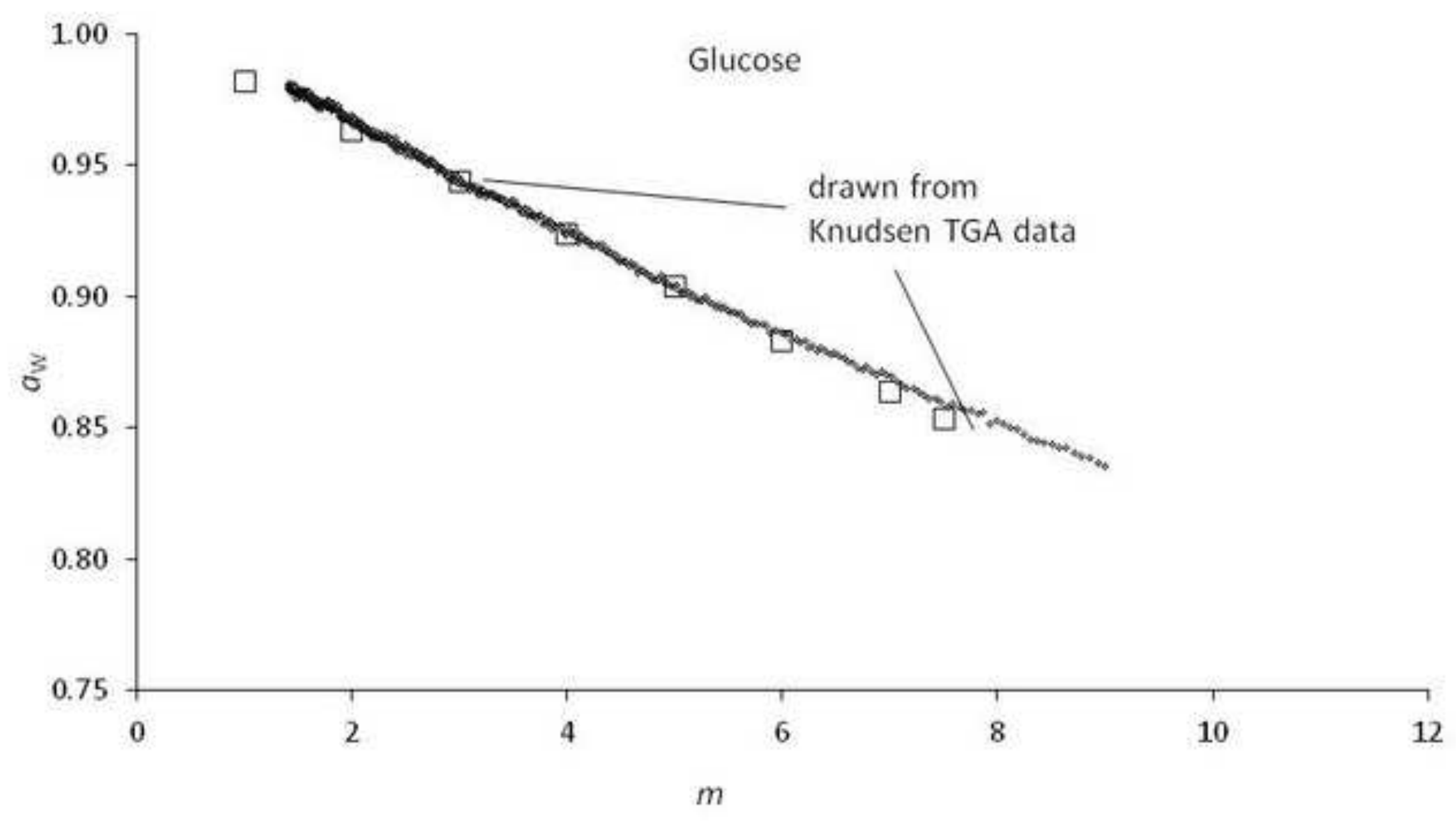

drawn from

Kudsen TGA data

, 
Click here to download high resolution image

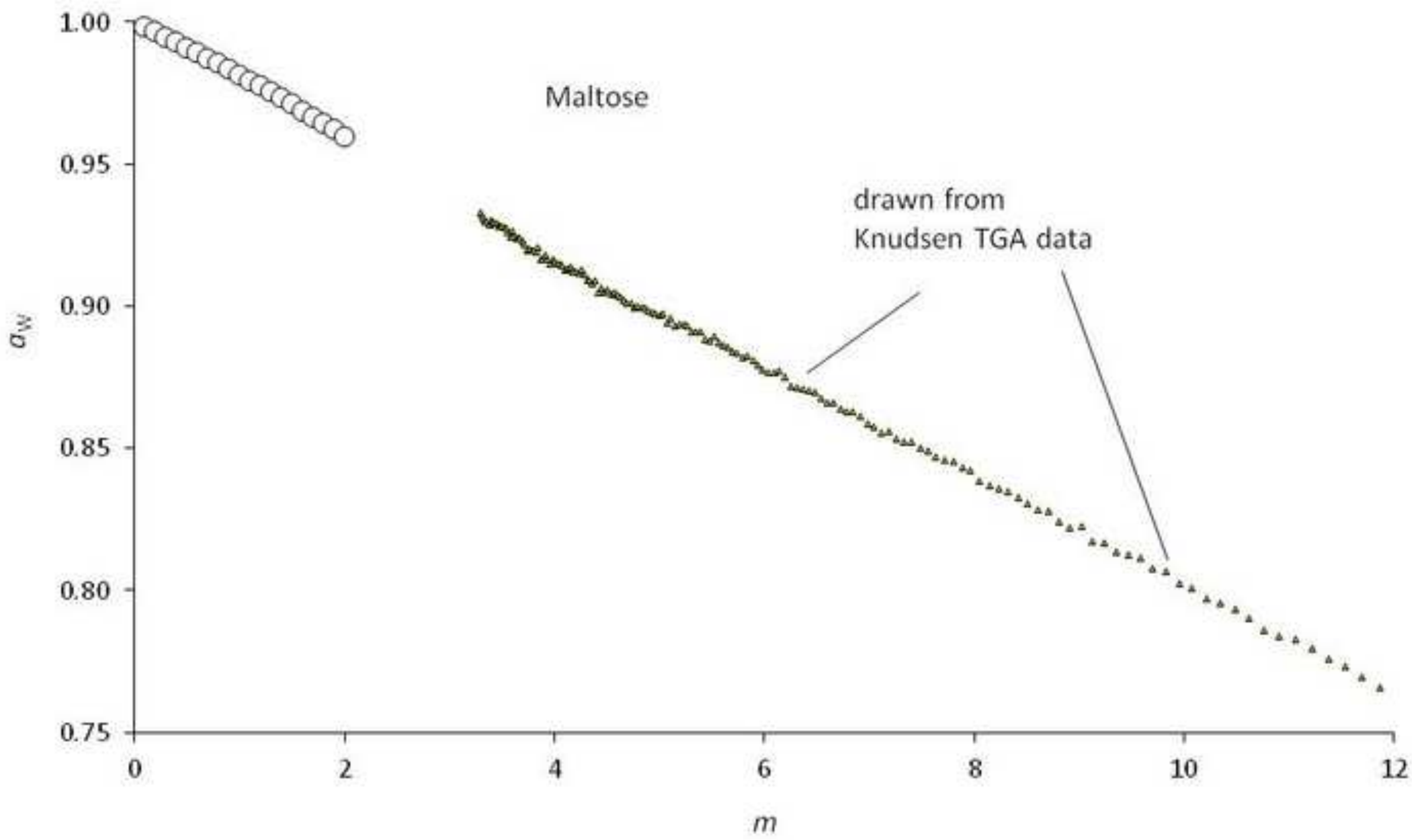


Click here to download high resolution image

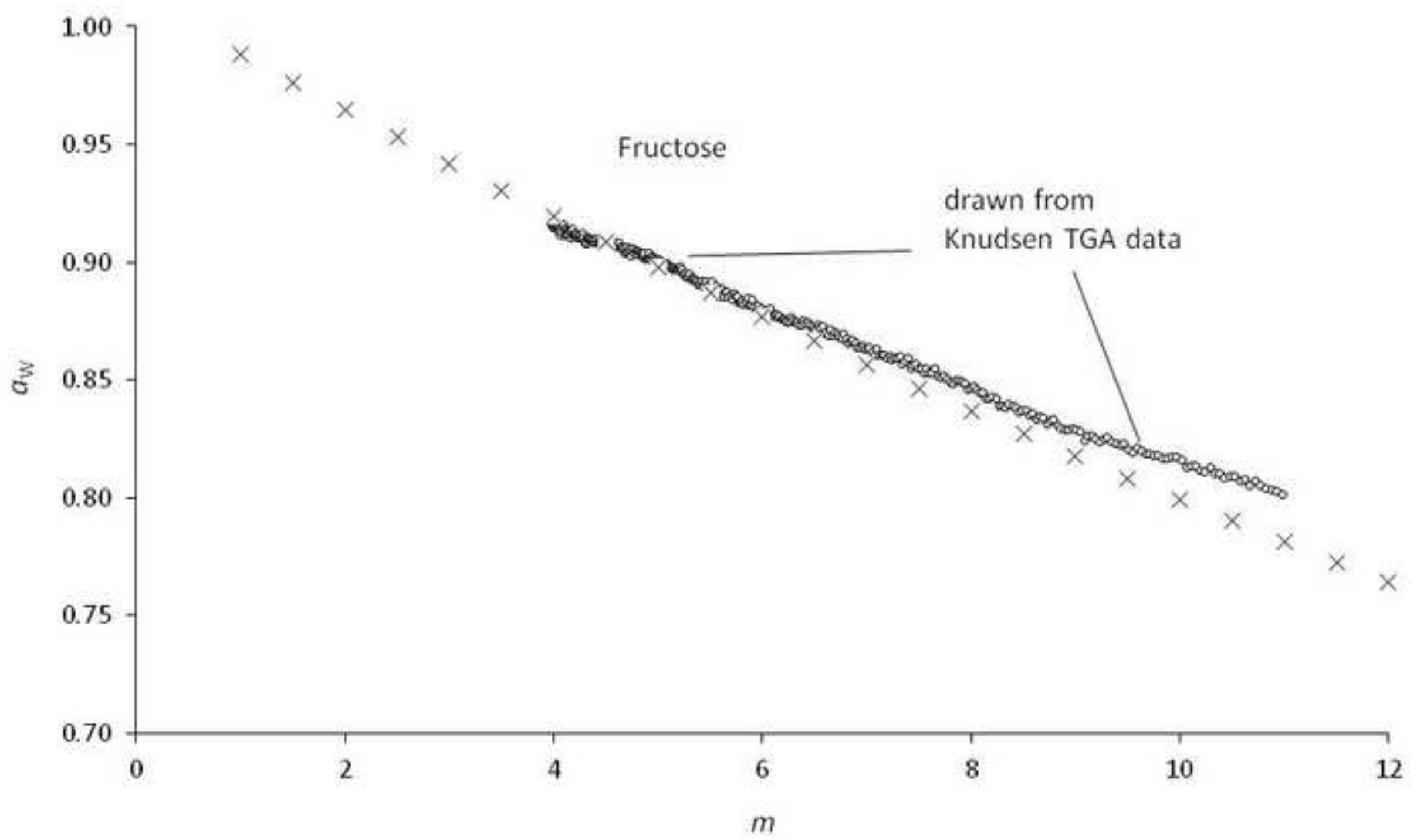


Click here to download high resolution image

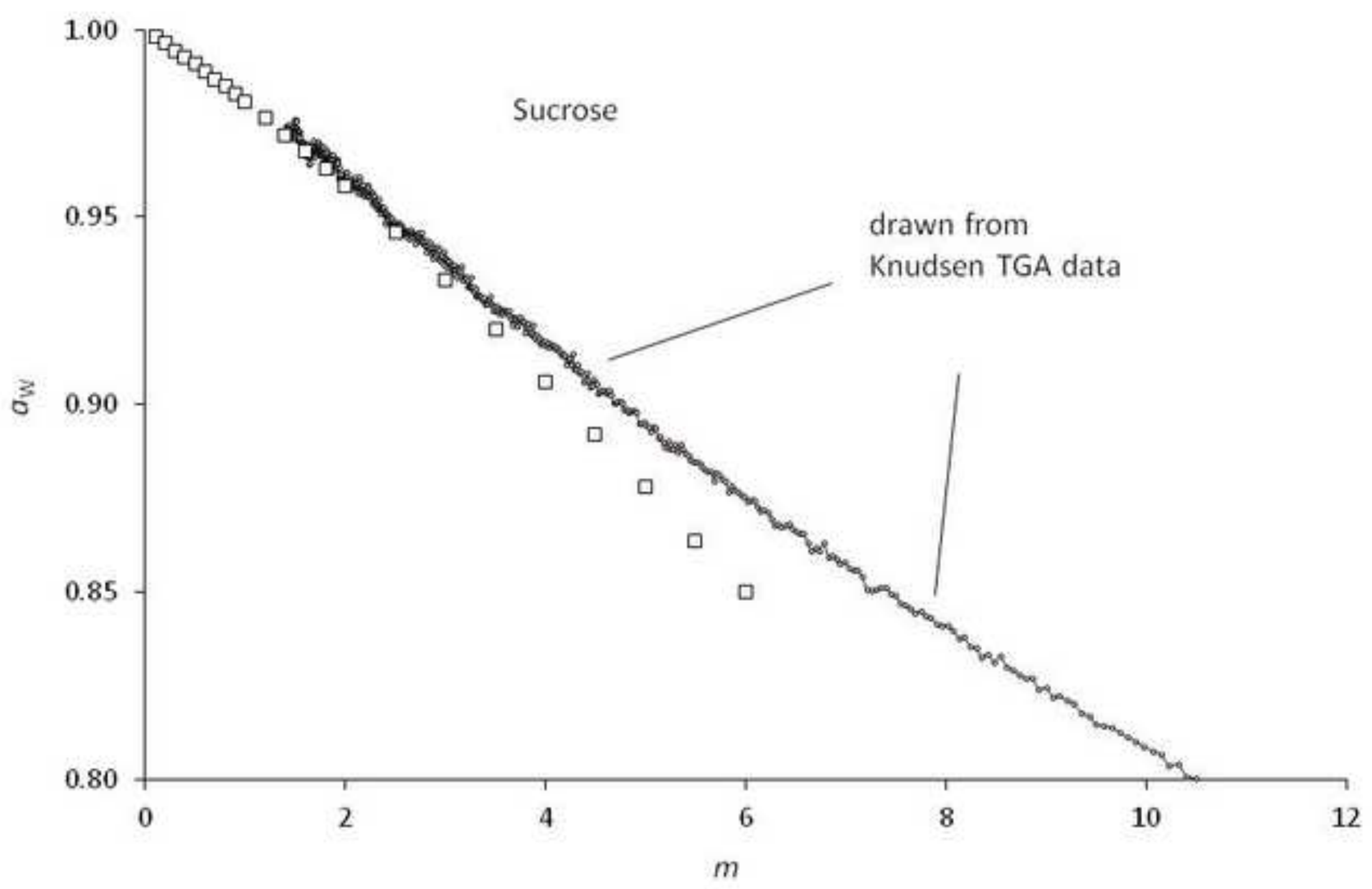

